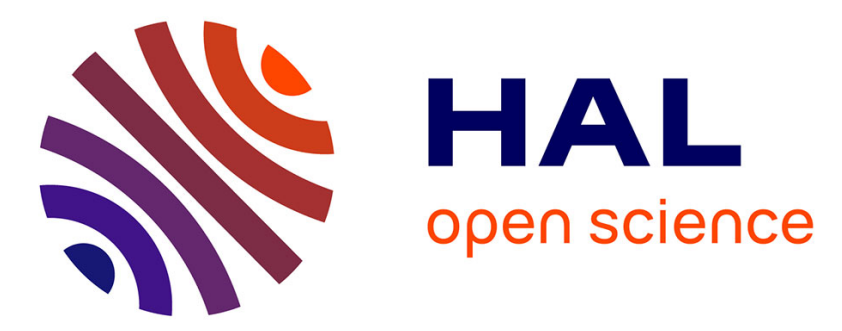

\title{
Kinetic model for hydrogen absorption in tungsten with coverage dependent surface mechanisms
}

Etienne A Hodille, S. Markelj, M Peccovnik, M Ajmalghan, Z A Piazza, Y. Ferro, T. Schwarz-Selinger, C. Grisolia

\section{- To cite this version:}

Etienne A Hodille, S. Markelj, M Peccovnik, M Ajmalghan, Z A Piazza, et al.. Kinetic model for hydrogen absorption in tungsten with coverage dependent surface mechanisms. Nuclear Fusion, In press, 10.1088/1741-4326/aba454 . hal-02901341

\section{HAL Id: hal-02901341 \\ https://hal.science/hal-02901341}

Submitted on 17 Jul 2020

HAL is a multi-disciplinary open access archive for the deposit and dissemination of scientific research documents, whether they are published or not. The documents may come from teaching and research institutions in France or abroad, or from public or private research centers.
L'archive ouverte pluridisciplinaire HAL, est destinée au dépôt et à la diffusion de documents scientifiques de niveau recherche, publiés ou non, émanant des établissements d'enseignement et de recherche français ou étrangers, des laboratoires publics ou privés. 
Postprint of article accpeted for publication in Nuclear Fusion as:

https://doi.org/10.1088/1741-4326/aba454

\title{
Kinetic model for hydrogen absorption in tungsten with coverage dependent surface mechanisms
}

\author{
E A Hodille ${ }^{1}$, S Markelj ${ }^{2}$, M Pecčovnik ${ }^{2}$, M Ajmalghan ${ }^{3}, \mathrm{Z}$ \\ A Piazza ${ }^{3}$, Y Ferro ${ }^{3}$, T Schwarz-Selinger ${ }^{4}$ C Grisolia ${ }^{1}$ \\ 1 CEA, IRFM, F-13108 Saint Paul Lez Durance, France \\ 2 Jožef Stefan Institute, Jamova cesta 39, 1000 Ljubljana, Slovenia \\ 3 Aix-Marseille Université-CNRS, PIIM UMR 7345, 13397 Marseille, France \\ ${ }^{4}$ Max-Planck-Institut für Plasmaphysik, Boltzmannstrasse 2, D-85748 \\ Garching, Germany \\ E-mail: etienne.hodille@gmail.com
}

\begin{abstract}
In this work, a kinetic model is presented to describe hydrogen absorption and desorption from tungsten at different surface coverages. Activation energies for hydrogen absorption into the bulk and desorption from the surface of tungsten are modelled by functions that depend explicitly and continuously on the hydrogen surface coverage. A steady-state model is developed to derive these activation energies from experimental data. The newly developed coverage dependent activation energies are then implemented in the non steady-state rate-equation code MHIMS. Published experimental results on D uptake and retention of self-damaged tungsten exposed to $0.28 \mathrm{eV}$ deuterium atoms at different temperatures ranging from $450 \mathrm{~K}$ to $1000 \mathrm{~K}$ can be successfully described with this approach. Finally, the steady-state model is applied to determine surface concentration, bulk concentration and migration depths of hydrogen isotopes in tungsten exposed to various atomic fluxes and temperatures ranging from milder conditions in laboratory experiments to divertor strike point conditions in tokamaks.
\end{abstract}

Keywords: tungsten, deuterium, surface mechanisms, fuel retention, rate-equation modeling 


\section{Introduction}

Fuel retention and released from tungsten (W) are key issues in the development of fusion as a source of energy. Due to safety issues regarding tritium, a strict $700 \mathrm{~g}$ operation limit has been imposed on ITER, but other physical processes are also of concern. For example, the release of the in-wall tritium inventory back into the plasma could have an adverse effect on plasma control [1]. Macroscopic rate equation (MRE) models are commonly used to estimate fuel retention and recycling into and from metals; these models couple the diffusion equation from Fick's laws and kinetic equations describing the interactions between the diffusing species and the lattice defects (trapping and detrapping) in the bulk of tungsten $[2,3,4,5,6]$. However, improvements of the MRE models in the vicinity of the surface are still necessary.

Experimental results by 't Hoen et al [7] suggest that loading of low energetic deuterium (D) ions $(<5$ $\mathrm{eV} / \mathrm{D}$ ) into $\mathrm{W}$ is limited by surface processes. To take this into account, MRE models have recently been upgraded $[8,9,10,11]$ with a kinetic surface model that acts as a boundary condition for the solute D concentration inside the $\mathrm{W}$ bulk. The main parameters of such a model are the activation energy of two recombined $\mathrm{D}$ atoms from the surface $2 E_{D}\left(E_{D}\right.$ per atom [12]), the absorption energy of D from the surface to the bulk $E_{A}$ and the resurfacing energy $E_{R}$, which describes a solute D atom moving from the bulk to the surface.

Pioneering studies on tungsten monocrystalline surfaces have shown that tungsten has different hydrogen adsorption sites depending on the crystal orientation [13]. The population of different adsorption sites is dependent on the surface coverage and on the sample temperature and because of this the activation energy for desorption $E_{D}$ also changes with surface coverage and temperature $[13,14,15]$. The temperature dependence of surface coverage was also shown experimentally on polycrystalline $\mathrm{W}[16]$. In addition, recent density functional theory (DFT) calculations [17, 18, 19] also report changes of the mechanism for absorption and desorption with the surface coverage $(\theta)$ : the corresponding $E_{D}$ and $E_{A}$ values were calculated and shown to be highly dependent on $\theta$.

Until recently, macroscopic rate equation (MRE) surface model did not take into account the surface coverage dependence of the activation energy for hydrogen desorption $E_{D}$ (which consequently influences also the energy for absorption $E_{A}$ ). However, in our previous simulations of $\mathrm{W}$ exposed to $0.28 \mathrm{eV} / \mathrm{D}$ atoms [8], the influence of surface coverage on the activation energies $E_{D}$ and $E_{A}$ had to be included to achieve good agreement between experiment and modelling for D exposures at $500 \mathrm{~K}$ ant $600 \mathrm{~K}$. The aim of the present work is to describe how the dependence of activation energies on surface coverage was derived. This is done in the present work by modelling the activation energies for deuterium desorption and absorption by continuious functions of the surface coverage $\theta, E_{D}(\theta)$ and $E_{A}(\theta)$, respectively, and by including these parameters in the kinetic model.

To this end, the continuous function $E_{D}(\theta)$ is first fitted to desorption energies determined experimentally in [16]. The $E_{A}(\theta)$ function is then obtained by making use of the steady-state model described below and the experimental data from Markelj et al [20, 21]. The experimental data consist of deuterium depth profiles of $\mathrm{W}$ samples that were irradiated with $\mathrm{MeV}$ energy $\mathrm{W}$ ions and exposed to $0.28 \mathrm{eV} / \mathrm{D}$ atoms at temperatures ranging from $450 \mathrm{~K}$ to $1000 \mathrm{~K}$. To adjust $E_{A}(\theta)$, the experimentally determined concentration of trapped deuterium $c_{\mathrm{D}}^{\exp }$ at a given flux and exposure temperature is given to a steady-state model which returns the corresponding value of $E_{A}(\theta)$. Once the $E_{A}(\theta)$ function established, it is implemented alongside with $E_{D}(\theta)$ in the non steady-state code MHIMS (Migration of Hydrogen Isotopes in Materials) [8]. Modelling results are compared with published experimental results from [20, 21] and yield excellent agreement with respect to diffusion depth and trapped deuterium concentration. Finally, the impact of the exposure condition (temperature and atom flux) on the values of surface energy, $\mathrm{H}$ coverage, $\mathrm{H}$ bulk concentration and migration depth are investigated and presented.

\section{Description of the model}

\subsection{General model}

In this paper, we use the $1 \mathrm{D}$ rate equation model commonly used to describe the behavior of deuterium in $\mathrm{W}[2,5]$, which was recently upgraded to take into account the surface processes $[8,9,10,11]$. In this model, three kinds of sites for particles (deuterium atoms) are considered:

- Surface sites - on the W surface, the total concen- 
tration of available adsorption sites is $n_{\text {surf }}\left(\mathrm{m}^{-2}\right)$, the concentration of adsorbed particles (filled adsorption site) is $c_{\text {surf }}\left(\mathrm{m}^{-2}\right)$, and the surface coverage $\theta$ is defined as $\theta=\frac{c_{\text {surf }}}{n_{\text {surf }}}$.

- Bulk sites for mobile particles - in perfect bulk $\mathrm{W}$, the total concentration of available sites for mobile particles, i.e. subjected to diffusion, is the concentration of tetrahedral interstitial sites $n_{\text {TIS }}$ $\left(\mathrm{m}^{-3}\right)$, and the concentration of mobile particles (filled interstitial sites) is $c_{\mathrm{m}}\left(\mathrm{m}^{-3}\right)$.

- Trap sites - in defective $\mathrm{W}$, the concentration of available traps of type $i$ is $n_{\mathrm{t}, i}\left(\mathrm{~m}^{-3}\right)$, and the concentration of trapped particle at trap sites $i$ is $c_{\mathrm{t}, i}\left(\right.$ in $\left.\mathrm{m}^{-3}\right)$.

It is assumed that the concentration of traps is low relatively to the concentration of interstitial sites $\left(n_{i} \ll n_{\text {TIS }}\right)$ and that the concentration of mobile particles stays much smaller than the concentration of interstitial sites $\left(c_{\mathrm{m}} \ll n_{\text {TIS }}\right)$. With these assumptions, the model allowing each trap site to capture one hydrogen is given by the following equations [8], giving the time evolution of the trapped and mobile particles in the bulk:

$\frac{\partial c_{\mathrm{m}}}{\partial t}=\frac{\partial}{\partial x}\left(D(T) \frac{\partial c_{\mathrm{m}}}{\partial x}\right)-\Sigma_{i} \frac{\partial c_{\mathrm{t}, i}}{\partial t}$

$\frac{\partial c_{\mathrm{t}, i}}{\partial t}=\nu_{\mathrm{m}}(T) c_{\mathrm{m}}\left(n_{i}-c_{\mathrm{t}, i}\right)-\nu_{i}(T) c_{\mathrm{t}, i}$

$D(T)\left(\mathrm{m}^{2} \mathrm{~s}^{-1}\right)$ is the diffusion coefficient of mobile $\mathrm{D}$ atoms in $\mathrm{W}$ as a function of temperature. It is equal to $D(T)=\frac{1.9 \times 10^{-7}}{\sqrt{2}} \exp \left(-\frac{0.2 \mathrm{eV}}{k_{\mathrm{B}} T}\right)$ as calculated by density functional theory calculations for hydrogen $[22](\sqrt{2}$ is to take into account the mass difference between deuterium and hydrogen), with $k_{\mathrm{B}}$ the Boltzmann constant. $\nu_{\mathrm{m}}(T)=\frac{D(T)}{\lambda^{2} n_{\mathrm{TIS}}}\left(\mathrm{m}^{3} \mathrm{~s}^{-1}\right)$ is the trapping rate constant with $\lambda=110 \times 10^{-12}$ $\mathrm{m}$ being the distance between two interstitial sites. $\nu_{i}(T)=\nu_{0} \exp \left(-\frac{E_{\mathrm{t}, i}}{k_{\mathrm{B}} T}\right)\left(\mathrm{s}^{-1}\right)$ is the detrapping rate constant with the pre-exponential factor $\nu_{0}=10^{13} \mathrm{~s}^{-1}$ factor and the detrapping energy $E_{\mathrm{t}, i}(\mathrm{eV})$.Recently, new models have been developed to describe a more accurate hydrogen trapping behavior in defects. Based on atomic calculations $[22,23,24,25,26]$, these models consider that a defect can trap several hydrogen atoms and the detrapping energies depends on filling level of the defect. The descriptions of these models can be found in $[27,28,29]$. The filldependent trapping mechanism is essential to simulate the isotopic exchange at low temperature as shown in [27] but has also been used to reproduce desorption experiments $[28,30,31]$. However, in the latter case, if only one $\mathrm{H}$ isotope is considered, both models give the same results [4]. Hence, we use the standard model (eq. 1 and 2) in the next.

The surface model, described in more detail in [8], acts as a boundary condition for the concentration of mobile particles. It describes the evolution of the concentration of deuterium adsorbed on the $\mathrm{W}$ surface and the concentration of mobile particles just below the surface for $\mathrm{x}=0$, where $\mathrm{x}$ represents the spatial coordinate of the 1-D model (i.e. the surface boundary is at $\mathrm{x}=0$ ). It is governed by the following conditions:

$$
\begin{aligned}
& \frac{\partial c_{\text {surf }}}{\partial t}=\phi_{\text {atom }}-\phi_{\text {exc }}-\phi_{\text {des }}-\phi_{\text {surf } \rightarrow \text { bulk }}+\phi_{\text {bulk } \rightarrow \text { surf }} \\
& \lambda\left(\frac{\partial c_{\mathrm{m}}}{\partial t}\right)_{x=0}=\phi_{\text {surf } \rightarrow \text { bulk }}-\phi_{\text {bulk } \rightarrow \text { surf }}-\phi_{\text {diff }}
\end{aligned}
$$

The expression of the different fluxes in the equations of the surface model are:

- $\phi_{\text {atom }}=\left(1-P_{\mathrm{r}}\right) \Gamma_{\mathrm{D}}(1-\theta)$ is the part of the incident flux which sticks to the surface with $P_{\mathrm{r}}$ the reflection coefficient of $\mathrm{D}$ atoms for a given energy and $\Gamma_{\mathrm{D}}\left(\mathrm{m}^{-2} \mathrm{~s}^{-1}\right)$ the incident flux of atoms.

- $\phi_{\text {exc }}=\Gamma_{\mathrm{D}} \sigma_{\mathrm{exc}} c_{\mathrm{surf}}$ is the direct abstraction of chemisorbed D (recombination of an incident atom with an adsorbed one) with $\sigma_{\text {exc }}\left(\mathrm{m}^{-2}\right)$ the crosssection for the abstraction.

- $\phi_{\text {des }}=2 \nu_{\mathrm{d}}(T) c_{\mathrm{surf}}^{2}$ is the desorption flux of two chemisorbed atoms with $\nu_{\mathrm{d}}(T)=$ $\nu_{0} \lambda_{\mathrm{des}}^{2} \exp \left(-\frac{2 E_{D}}{k_{\mathrm{B}} T}\right)$, the desorption rate constant in $\mathrm{m}^{2} \mathrm{~s}^{-1} ; \lambda_{\text {des }}=\frac{1}{\sqrt{n_{\text {surf }}}}(\mathrm{m})$ is the jumping distance between two adsorption sites and $2 E_{D}(\mathrm{eV})$ is the activation energy for the desorption of the $\mathrm{D}_{2}$ molecules.

- $\phi_{\text {surf } \rightarrow \text { bulk }}=\nu_{\mathrm{sb}}(T) c_{\mathrm{surf}}$ is the absorption flux from the surface to the bulk with $\nu_{\mathrm{sb}}(T)=$ $\nu_{0} \exp \left(-\frac{E_{A}}{k_{\mathrm{B}} T}\right)$, the absorption rate constant in $\mathrm{s}^{-1} ; E_{A}(\mathrm{eV})$ is the activation energy for the absorption.

- $\phi_{\text {bulk } \rightarrow \text { surf }}=\nu_{\text {bs }}(T) c_{\mathrm{m}}(x=0)(1-\theta)$ is the flux from the bulk to the surface with $\nu_{\mathrm{bs}}(T)=$ $\nu_{0} \lambda_{\text {abs }} \exp \left(-\frac{E_{R}}{k_{\mathrm{B}} T}\right)$, the bulk to surface rate constant in $\mathrm{m}^{1} \mathrm{~s}^{-1} ; \lambda_{\mathrm{abs}}=\frac{n_{\text {surf }}}{n_{\mathrm{TIS}}}$ is the jumping distance from the bulk to the surface and $E_{R}(\mathrm{eV})$ is the energy barrier.

- $\phi_{\text {diff }}=-D(T)\left(\frac{\partial c_{\mathrm{m}}}{\partial x}\right)_{x=0}$ is the diffusion flux at $\mathrm{x}=0$ toward the bulk.

The parameters of the model are given in detail in Table 1. Parameters such as $\lambda_{\text {des }}$ and $\lambda_{\text {abs }}$ neglect crystallographic dependencies but are effective values derived from bulk densities. In this model, an atom is considered absorbed in the bulk as soon as it is below the first $\mathrm{W}$-atom layer. Thus, this description does 
not include the sub-surface layer described by atomistic simulation in $[18,32]$ where the stable positions of $\mathrm{H}$ atoms close to the surface are lower in energy than in the far bulk. To include such a layer in the model, one could use what is developed for $\mathrm{H}$ absorption in titanium in [33] where another intermediate layer is considered between the surface and the bulk: it means adding 2 new energies (for the sub-surface $\rightarrow$ surface transition and for the sub-surface $\rightarrow$ bulk transition) and an additional concentration of $\mathrm{H}$ isotopes in this sub-surface layer. However, because the experiment on which the model is based does not have the resolution to dicern the sub-surface from the bulk, the simpleer approach was chosen.

This model is implemented in the code MHIMS [5, $8]$ in which equations 1-4 are solved numerically using the DLSODE package [34, 35]. MHIMS is used in this study for the non steady state simulations.

\subsection{Steady-state model}

Considering the above model at steady state conditions, simple analytical expressions can be established for $E_{D}, E_{A}, c_{\mathrm{surf}}, c_{\mathrm{m}}$ and the total D concentration $c_{\mathrm{D}}$. This model will be referred as the steady-state model in this work.

2.2.1. Steady-state of the surface First, we consider that the surface is at steady-state meaning that $\frac{\partial c_{\text {surf }}}{\partial t}=0$ and $\left(\frac{\partial c_{\mathrm{m}}}{\partial t}\right)_{x=0}=0$. In this equilibrium state, the surface energies and the concentrations in the surface model are linked by unique expressions given in the following. The surface energies and concentrations in this equilibrium state are thus named $E_{D}^{\mathrm{eq}}, E_{A}^{\mathrm{eq}}, c_{\mathrm{surf}}^{\mathrm{eq}}, \theta^{\mathrm{eq}}$ and $c_{\mathrm{m}}^{\mathrm{eq}}$. We also assume that the diffusive flux of particles from $\mathrm{x}=0$ toward the bulk is negligible compared to the flux $\phi_{\text {bulk } \rightarrow \text { surf }}: \phi_{\text {diff }} \approx 0$. The justification for this assumption can be found in appendix A.

With the above assumption, the steady-state of equation 4 leads to:

$\phi_{\text {surf } \rightarrow \text { bulk }}-\phi_{\text {bulk } \rightarrow \text { surf }}=0$

When substituted into equation 3 , it leads to:

$-2 \nu_{\mathrm{d}}(T)\left(c_{\text {surf }}^{\mathrm{eq}}\right)^{2}-\omega_{1} c_{\text {surf }}^{\mathrm{eq}}+\omega_{2}=0$

with

$\omega_{1}=\left(\frac{1-P_{r}}{n_{\text {surf }}}+\sigma_{\text {exc }}\right) \Gamma_{\mathrm{D}}$

$\omega_{2}=\left(1-P_{r}\right) \Gamma_{\mathrm{D}}$.

Since $\nu_{d}(T)=\nu_{0} \lambda_{\text {des }}^{2} \exp \left(-\frac{2 E_{D}}{k_{\mathrm{B}} T}\right)$, equation 6 leads to:

$E_{D}^{\mathrm{eq}}=-\frac{k_{\mathrm{B}} T}{2} \ln \left[\frac{1}{\lambda_{\mathrm{des}}^{2} \nu_{0}}\left(\frac{\omega_{2}}{2\left(c_{\mathrm{surf}}^{\mathrm{eq}}\right)^{2}}-\frac{\omega_{1}}{2 c_{\mathrm{surf}}^{\mathrm{eq}}}\right)\right]$ which provides the steady-state value of $E_{D}$ as a function of the surface coverage under a given exposure condition. Since equation 9 depends on $c_{\text {surf }}^{\text {eq }}$, it consequently provides $E_{D}^{\mathrm{eq}}$ as a function of $\theta^{\mathrm{eq}}$.

Another point to be aware of is that, due to the direct abstraction by the incident atomic flux, the surface concentration at steady-state is limited to a maximum value $\theta_{\max }<1$ [8]. With the chosen parameters given in table $1, \theta_{\max }=0.505$. This maximum surface concentration is reached when the desorption of deuterium is very low (low temperature leading to $\nu_{\mathrm{d}}(T) \rightarrow 0$ ) or if the flux is very high $\left(\Gamma_{\mathrm{D}} \rightarrow \infty\right)$. In these conditions, equation 6 leads to:

$\theta_{\max }=\frac{c_{\mathrm{surf}}^{\mathrm{eq}, \max }}{n_{\mathrm{surf}}}=\frac{1-P_{r}}{1-P_{r}+\sigma_{\mathrm{exc}} n_{\mathrm{surf}}}$.

The steady-state concentration of mobile particle is calculated using equation 5 replacing $\phi_{\text {surf } \rightarrow \text { bulk }}$ and $\phi_{\text {bulk } \rightarrow \text { surf }}$ by their expression given in section 2.1:

$c_{\mathrm{m}}^{\mathrm{eq}}(x=0)=\frac{\nu_{\mathrm{sb}}(T)}{\nu_{\mathrm{bs}}(T)} \frac{c_{\mathrm{surf}}^{\mathrm{eq}}}{1-\theta^{\mathrm{eq}}}$

In this study, it is considered that $E_{R}=0.2 \mathrm{eV}$ [8]. Since $\frac{\nu_{\mathrm{sb}}(T)}{\nu_{\mathrm{bs}}(T)} \propto \exp \left(-\frac{E_{A}^{\mathrm{eq}}-E_{R}}{k_{\mathrm{B}} T}\right)$, if $E_{A}^{\mathrm{eq}}$ and $c_{\mathrm{surf}}^{\mathrm{eq}}$ are known, the concentration of mobile particles can be obtained with equation 11 . Reversely, if $c_{\mathrm{m}}^{\mathrm{eq}}$ and $c_{\mathrm{surf}}^{\mathrm{eq}}$ are known, $E_{A}^{\mathrm{eq}}$ is determined inverting equation 11 , and leading to:

$E_{A}^{\mathrm{eq}}=E_{R}-k_{\mathrm{B}} T \ln \left[\frac{c_{\mathrm{m}}^{\mathrm{eq}} \lambda_{\mathrm{abs}}}{c_{\mathrm{surf}}^{\mathrm{eq}}}\left(1-\theta^{\mathrm{eq}}\right)\right]$

2.2.2. Steady-state in the bulk Now, we consider that at the depth $x$, the mobile and trapped particles are in local equilibrium (i.e. the concentration of particles at interstitial sites and trap sites is time independent). Thus, $\frac{\partial c_{t, i}}{\partial t}=0$, which leads to:

$c_{\mathrm{t}, i} \quad=R_{\mathrm{t}, i}\left(T, c_{\mathrm{m}}\right) n_{i}$
$R_{\mathrm{t}, i}\left(T, c_{\mathrm{m}}\right)=\frac{1}{1+\frac{\nu_{i}(T)}{\nu_{\mathrm{m}}(T) c_{\mathrm{m}}}}$

In equation $14, R_{\mathrm{t}, i}\left(T, c_{\mathrm{m}}\right)$, called the trapping-ratio, is between 0 and 1 ; it expresses the fraction of traps of type $i$ which are filled by deuterium at a given temperature. It is dependent on the local concentration of mobile particles $c_{\mathrm{m}}$. The higher $c_{\mathrm{m}}$, the higher the trapping-ratio $R_{\mathrm{t}, i}\left(T, c_{\mathrm{m}}\right)$, and the higher the concentration of deuterium $c_{\mathrm{t}, i}$ trapped in trap $i$.

As mentioned in the previous section, the fill-level dependent trapping models are also used to simulate exposure, desorption or isotopic exchange experiments. The results given by equation 14 to estimate the concentration of trapped $\mathrm{H}$ isotope can be extended to a fill-level dependent model following the method 
Table 1: Quantities of interest for the steady-state analysis of the kinetic surface and bulk model (input parameters from experiments (1), parameters in the bulk model (2), parameters in the surface model (3)). TIS $=$ tetrahedral interstitial site. $k_{\mathrm{B}}$ is the Boltzmann constant.

\begin{tabular}{|c|c|c|c|c|}
\hline \multirow[t]{2}{*}{1} & $\Gamma_{\mathrm{D}}$ & Incident flux of atoms $\left(\mathrm{Dm}^{-2} \mathrm{~s}^{-1}\right)$ & From experiments & {$[20,21]$} \\
\hline & $T$ & Temperature $(\mathrm{K})$ & From experiments & {$[20,21]$} \\
\hline \multirow{9}{*}{2} & $\rho_{\mathrm{W}}$ & $\mathrm{W}$ atomic density $\left(\mathrm{m}^{-3}\right)$ & $6.3 \times 10^{28}$ & \\
\hline & $D(T)$ & Diffusion coefficient of deuterium $\left(\mathrm{m}^{2} \mathrm{~s}^{-1}\right)$ & $\frac{1.9 \times 10^{-7}}{\sqrt{2}} \exp \left(-\frac{0.2 \mathrm{eV}}{k_{\mathrm{B}} T}\right)$ & {$[22]$} \\
\hline & $\lambda$ & Distance between two TIS (m) & $110 \times 10^{-12}$ & {$[22]$} \\
\hline & $n_{\text {TIS }}$ & Concentration of TIS $\left(\mathrm{m}^{-3}\right)$ & $6 \rho_{\mathrm{W}}$ & {$[22]$} \\
\hline & $n_{i}$ & Concentration of trap sites $i$ & From MHIMS simulations & {$[8,36]$} \\
\hline & $E_{\mathrm{t}, i}$ & Detrapping energy from trap $i$ & From MHIMS simulations & {$[8,36]$} \\
\hline & $\nu_{\mathrm{m}}(T)$ & Trapping rate constant $\left(\mathrm{m}^{3} \mathrm{~s}^{-1}\right)$ & $\frac{D(T)}{n_{\operatorname{TIS} \lambda^{2}}}$ & {$[8]$} \\
\hline & $\nu_{0}$ & Pre-exponential factor (trapping and surface) $\left(\mathrm{s}^{-1}\right)$ & $10^{13}$ & {$[8]$} \\
\hline & $\nu_{i}(T)$ & Detrapping rate constant from trap type $i\left(\mathrm{~s}^{-1}\right)$ & $\nu_{0} \exp \left(-\frac{E_{\mathrm{t}, i}}{k_{\mathrm{B}} T}\right)$ & {$[8]$} \\
\hline \multirow{11}{*}{3} & $1-P_{r}$ & Sticking probability of $\mathrm{D}$ atoms & 0.19 for $0.28 \mathrm{eV} / \mathrm{D}$ atoms & {$[37]$} \\
\hline & $\sigma_{\text {exc }}$ & Cross-section for the direct abstraction $\left(\mathrm{m}^{2}\right)$ & $1.7 \times 10^{-21}$ & {$[38]$} \\
\hline & $n_{\text {surf }}$ & Concentration of adsorption site $\left(\mathrm{m}^{-2}\right)$ & $6.9 \rho_{\mathrm{W}}^{\frac{2}{3}}$ & {$[38]$} \\
\hline & $E_{D}$ & Desorption energy per D (eV) & figure 1 , equation 9 & \\
\hline & $E_{A}$ & Activation energy from surface to bulk (eV) & figure 5 , equation 12 & \\
\hline & $E_{R}$ & Activation energy from bulk to surface $(\mathrm{eV})$ & $0.2 \mathrm{eV}$ & {$[8]$} \\
\hline & $\lambda_{\mathrm{des}}$ & Distance between two adsorption sites (m) & $\frac{1}{\sqrt{n_{\text {surf }}}}$ & {$[8]$} \\
\hline & $\lambda_{\mathrm{abs}}$ & Subsurface TIS - adsorption site distance (m) & $\frac{n_{\text {surf }}}{n_{\text {TIS }}}$ & {$[8]$} \\
\hline & $\nu_{\mathrm{d}}(T)$ & Rate constant for desorption process $\left(\mathrm{m}^{2} \mathrm{~s}^{-1}\right)$ & $\nu_{0} \lambda_{\mathrm{des}}^{2} \exp \left(-\frac{2 E_{D}}{k_{\mathrm{B}} T}\right)$ & {$[8]$} \\
\hline & $\nu_{\mathrm{sb}}(T)$ & Rate constant from surface to bulk $\left(\mathrm{s}^{-1}\right)$ & $\nu_{0} \exp \left(-\frac{E_{A}}{k_{\mathrm{B}} T}\right)$ & {$[8]$} \\
\hline & $\nu_{\mathrm{bs}}(T)$ & Rate constant from bulk to surface $\left(\mathrm{ms}^{-1}\right)$ & $\nu_{0} \lambda_{\mathrm{abs}} \exp \left(-\frac{E_{R}}{k_{\mathrm{B}} T}\right)$ & {$[8]$} \\
\hline
\end{tabular}

described in appendix B.

In the bulk, the total concentration $c_{\mathrm{D}}$ is split between $c_{\mathrm{m}}$ and $c_{\mathrm{t}, i}$ as defined by $c_{\mathrm{D}}=c_{\mathrm{m}}+\sum_{i} c_{\mathrm{t}, i}$. Within the temperature range $(450 \mathrm{~K}-1000 \mathrm{~K})$ and the fluxes $\left(\approx 10^{18} \mathrm{~m}^{-2} \mathrm{~s}^{-1}\right.$ and $\left.\approx 10^{19} \mathrm{~m}^{-2} \mathrm{~s}^{-1}\right)$ herein considered, $c_{\mathrm{m}} \leq 10^{-10}$ at.fr. [36] and $c_{\mathrm{t}, i} \geq 10^{-5}$ at.fr. $[8,36]$ due to the large detrapping energy $(>1.5$ $\mathrm{eV}$ ) of the defects created by the $\mathrm{W}$ irradiation in the damaged layer. Thus, we assume that $c_{\mathrm{m}} \ll c_{\mathrm{t}, i}$ and
$c_{\mathrm{D}} \approx c_{\mathrm{t}, i}$. This leads to :

$c_{\mathrm{D}} \approx \sum_{i} c_{\mathrm{t}, i}=\sum_{i} R_{\mathrm{t}, i}\left(T, c_{\mathrm{m}}\right) n_{i}$

As a consequence, the bulk steady-state model as presented herein can yield the steady-state values of $c_{\mathrm{t}, i}$. The inputs of such a model are the trapping parameters (i.e. the trap concentrations and the detrapping energies) and the concentration of mobile particles $c_{\mathrm{m}}$. 


\section{Fitting $E_{D}(\theta)$ from experiment}

The function $E_{D}(\theta)$ is established based on elastic recoil detection analysis of $\mathrm{H}$ and $\mathrm{D}$ adsorption on poly-crystalline W (PCW) from Markelj et al. [16]. In ref. [16], the experimental data were fitted with a kinetic adsorption/desorption model considering three adsorption sites. The corresponding desorption energies $2 E_{D}$ were $1.05 \pm 0.06 \mathrm{eV} \quad\left(E_{D}=0.525 \mathrm{eV}\right)$, $1.64-1.70 \pm 0.08 \mathrm{eV}\left(E_{D}=0.82-0.85 \mathrm{eV}\right)$ and $>2.2 \mathrm{eV}$ $\left(E_{D}=1.1 \mathrm{eV}\right)$. However, in order to plot $E_{D}$ versus $\theta$ in figure 1 , we need the areal density of adsorption sites $n_{\text {surf }}$ that determine $\theta$. It was assessed in Markelj et al. $[16]$ to be $4.6 \pm 0.9 \times 10^{19}, 1.0 \pm 0.1 \times 10^{19}$ and $1.2 \pm 0.2 \times 10^{19} \mathrm{~m}^{-2}$, respectively. The sum of the three adsorption sites is $6.8 \pm 0.6 \times 10^{19} \approx 4.3 \rho_{\mathrm{W}}^{\frac{2}{3}} \mathrm{~m}^{-2}$, meaning there are on average 4.3 adsorption sites per $\mathrm{W}$ atom for the samples used in this experiment and:

$E_{D}(\theta)= \begin{cases}1.1 \mathrm{eV}, & 0.00<\theta \leq 0.15 \\ 0.82-0.85 \mathrm{eV}, & 0.15<\theta \leq 0.32 \\ 0.525 \mathrm{eV}, & 0.32<\theta<1.00\end{cases}$

From these data, we applied a non-linear least square regression fit using SciPy's [39, 40] optimize.curve_fit module with the expression:

$E_{D}(\theta)=E_{0}+\Delta E \frac{1}{1+\exp \left(\frac{\theta-a}{b}\right)}$

where $E_{0}=0.525 \mathrm{eV}, \Delta E=0.591 \mathrm{eV}, a=0.247$ and $b=0.0692$. The representative curve of $E_{D}(\theta)$ is reported as solid line in figure 1 . The continuous variation of $E_{D}(\theta)$ is consistent with previous results indicating that the adsorbate-adsorbate interactions smooths $E_{D}$ [15] over the full range of $\theta$.

In the next, 2 sets of experimental data are

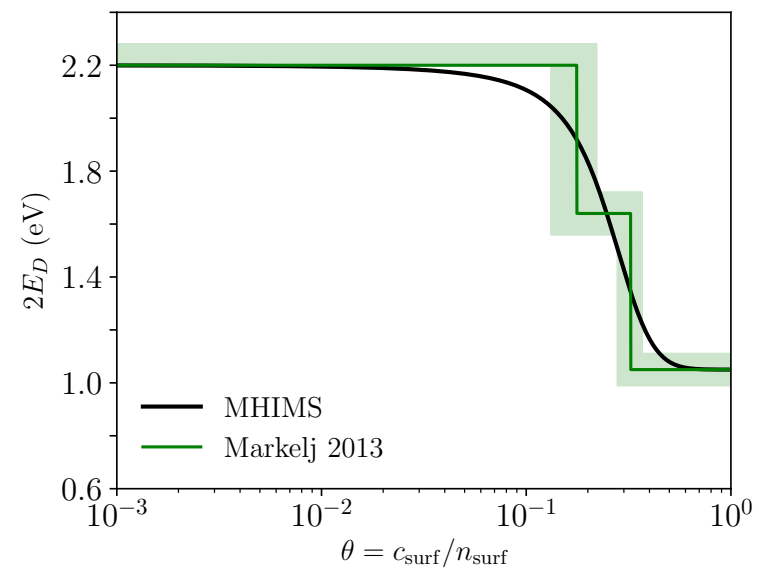

Figure 1: $2 E_{D}(\theta)$ implemented in MHIMS and reported by Markelj et al. [16]. The error bar provided by Markelj et al are also reported.

analysed using the steady-state model presented in
Table 2: Experimental D concentration, $c_{\mathrm{D}}^{\text {exp }}$, used for the determination of the coverage dependent surface energies of the kinetic surface model for experimental sets:

$\Gamma_{\mathrm{D}}^{1}=5.4 \times 10^{18} \mathrm{Dm}^{-2} \mathrm{~s}^{-1}$, $\Gamma_{\mathrm{D}}^{2}=3.5 \times 10^{19} \mathrm{Dm}^{-2} \mathrm{~s}^{-1}$.

\begin{tabular}{lcc}
\hline \hline & \multicolumn{2}{c}{$c_{\mathrm{D}}^{\text {exp }}$} \\
& set $1[20]$ & set $2[21]$ \\
$\Gamma_{\mathrm{D}}^{1}$ & $\Gamma_{\mathrm{D}}^{2}$ \\
\hline $450 \mathrm{~K}$ & $3.4 \times 10^{-3}$ at.fr. & - \\
$500 \mathrm{~K}$ & - & $6.5 \times 10^{-3}$ at.fr. \\
$600 \mathrm{~K}$ & $1.4 \times 10^{-3}$ at.fr. & $3.6 \times 10^{-3}$ at.fr \\
$700 \mathrm{~K}$ & - & $1.2 \times 10^{-3}$ at.fr. \\
$800 \mathrm{~K}$ & $2.6 \times 10^{-4}$ at.fr. & $3.2 \times 10^{-4}$ at.fr. \\
$900 \mathrm{~K}$ & $7.7 \times 10^{-5}$ at.fr. & $3.9 \times 10^{-5}$ at.fr. \\
$1000 \mathrm{~K}$ & $9.4 \times 10^{-5}$ at.fr. & - \\
\hline
\end{tabular}

section 2.2. In these experiments, W samples were irradiated by high energy W ions (self-damaged W). The concentration of adsorption site in this case is $n_{\text {surf }}=6.9 \rho_{\mathrm{W}}^{\frac{2}{3}} \approx 10 \times 10^{19} \mathrm{~m}^{-2}[8]$, meaning there are on average 6.9 adsorption sites per $\mathrm{W}$ atoms. This value is in agreement with some previous measurement on self-damaged $\mathrm{W}$ exposed to D atom at $380 \mathrm{~K}$ [38], but is higher than the one of the previous set of results with 4.3 adsorption sites per $\mathrm{W}$ atom, probably as a the consequence of the $\mathrm{W}$ ion bombardment and surface roughness. It is also higher than the experimental maximum surface coverage obtained at low temperature on clean, flat $\mathrm{W}$ surfaces which is around one or two adsorbed $\mathrm{H}$ per $\mathrm{W}$ atom $[13,41]$. We are left with the choice of which areal density $n_{\text {surf }}$ to use in the present study, using the above experimental data as a guide. In the following, $n_{\text {surf }}=6.9$ has been considered. However, changing $n_{\text {surf }}$ from 6.9 to 4.3 or smaller has only a small consequence on the models outcomes.

\section{Determination of $E_{A}(\theta)$}

\subsection{Description of the experimental data set used}

In order to determine the evolution of $E_{A}$ with coverage, we used experimental D depth profiles obtained in two experiments where $\mathrm{W}$ samples were first irradiated with $\mathrm{MeV} \mathrm{W}$ ions and afterwards exposed to $0.28 \mathrm{eV} / \mathrm{D}$ atoms [20, 21]. Thus, we divide the experimental data sets in set 1 for data from [20] and set 2 for data from [21]. From the experimental 
depth profiles, we extracted the $\mathrm{D}$ concentration $c_{\mathrm{D}}^{\mathrm{exp}}$ in the damaged layer. They are reported in table 2 for the different exposure temperatures and incident D fluxes used in these experiments. More detailed description of the experiments, for instance how the material has been damaged, can be found in appendix $\mathrm{C}$.

For the steady-state analysis, we use the trapping

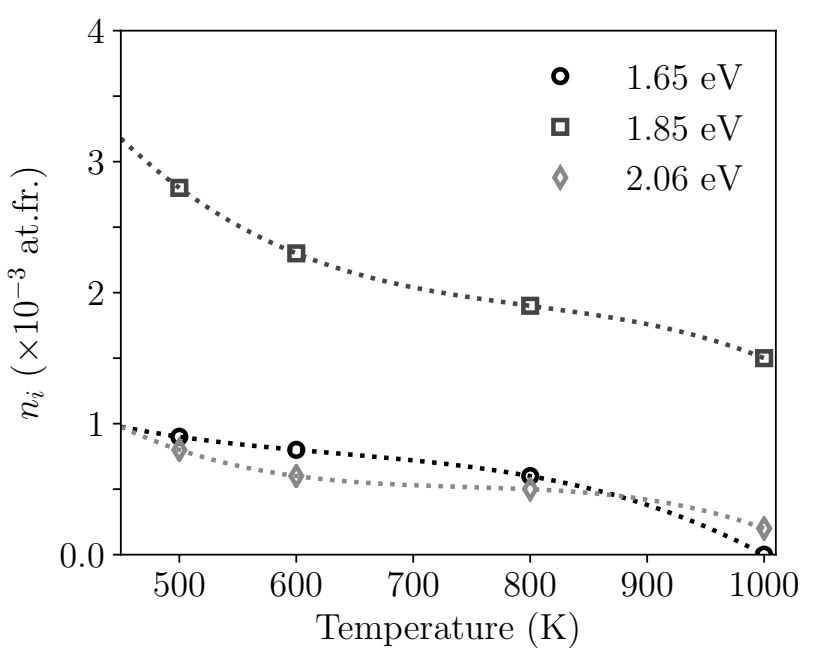

Figure 2: Evolution of the trap concentration $n_{i}$ (in at.fr.) with the exposure/annealing temperature for the traps in the damaged layer with the detrapping energies indicated in the legend. The markers represent the concentration obtained from our previous simulations [8] and the dashed lines are the interpolation in the range $450 \mathrm{~K}-1000 \mathrm{~K}$.

parameters to describe the trapping sites in the damaged layer, i.e. the detrapping energies and the trap concentrations. For the experimental data set 1 , the trapping parameters have been obtained in [36]: the damaged layer is simulated using 2 traps with detrapping energies of $1.83 \mathrm{eV}$ and $2.10 \mathrm{eV}$. The trap concentration can be found in [36] for the different exposure temperatures. For experimental data set 2, the trapping parameters were obtained in [8]: the damaged layer is simulated using 3 traps with detrapping energies of $1.65 \mathrm{eV}, 1.85 \mathrm{eV}$ and $2.06 \mathrm{eV}$ (the last two traps are the same as for experimental data set 1). Here, we use different exposure temperatures than those which were studied in [8] which might change the trap concentrations. An interpolation of the trap concentrations $n_{i}$ reported in [8] is done in the studied temperature range $(450 \mathrm{~K}$ - $1000 \mathrm{~K}$ ), shown in figure 2. The interpolation was done using the interpolate.UnivariateSpline function from the SCIPY. package [39, 40].

\subsection{Steady-state analysis}

As described in section 2.2, we made use of the steadystate model to sequentially determine:

(i) $c_{\text {surf }}^{\text {eq }}($ equation 9$)$,

(ii) then, $c_{\mathrm{m}}$ (equation 15$)$ needed to reach $c_{\mathrm{D}}^{\text {exp }}$,

(iii) and finally, the value of $E_{A}^{\mathrm{eq}}$ (equation 12).

This procedure is done for all exposure conditions of experimental data sets 1 and 2 .
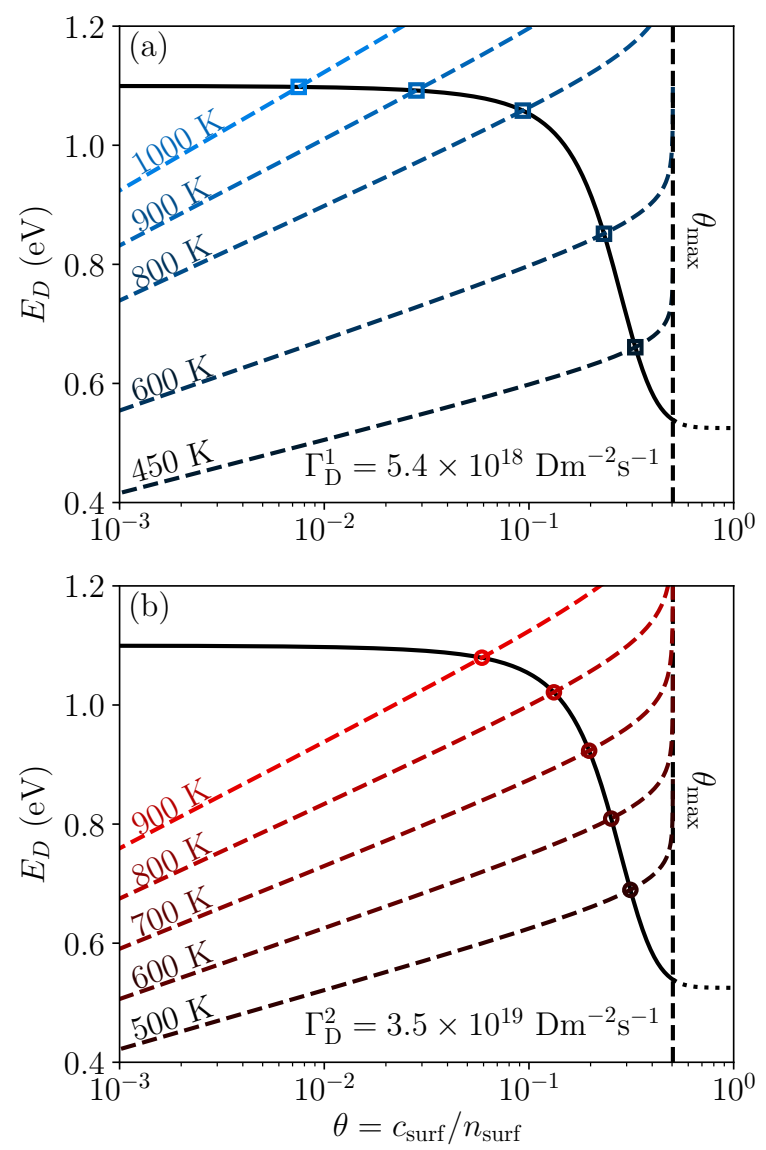

Figure 3: Determination of $E_{D}^{\mathrm{eq}}$ and coverage $\theta^{\mathrm{eq}}=$ $c_{\text {surf }}^{\text {eq }} / n_{\text {surf }}$ for the experimental conditions of data set 1 [20] (a) and data set 2 [21] (b). These values are determined by the intersection of the dashed lines (given by equation 9 ) and the solid line $\left(E_{D}(\theta)\right.$ shown in figure 1). The vertical dashed line shows the maximal value $\theta_{\max }$.

4.2.1. Steady-state value of $c_{\text {surf }}$ The surface concentration at steady-state $c_{\text {surf }}^{\text {eq }}$ is determined via the two expressions we established for $E_{D}$ :

- $E_{D}(\theta)$ given by equation 17 , was fitted to experimental data [16] and only depends on the surface coverage (or surface concentration), 
- $E_{D}^{\mathrm{eq}}$ given by equation 9 , depends on the temperature $T$, the deuterium flux to the surface $\Gamma_{\mathrm{D}}$, and the surface coverage at equilibrium $\theta^{\text {eq }}$ (proportional to $\left.c_{\text {surf }}^{\text {eq }}\right): E_{D}^{\mathrm{eq}}\left(T, \Gamma_{\mathrm{D}}, \theta^{\mathrm{eq}}\right)$. The temperature $T$ and the flux to the surface $\Gamma_{\mathrm{D}}$ are known from experiment. Only the surface coverage $c_{\text {surf }}^{\mathrm{eq}}$ is to be determined.

In figure $3, E_{D}^{\mathrm{eq}}$ and $E_{D}(\theta)$ are plotted for coverage ranging from $10^{-3}$ to $\theta_{\max }$. $c_{\text {surf }}^{\text {eq }}$ is determined where $E_{D}(\theta)$ and $E_{D}^{\mathrm{eq}}$ intersect for the various temperature and fluxes corresponding to the experimental data sets 1 and 2. The determined values of $\theta^{\mathrm{eq}}$ and $E_{D}^{\mathrm{eq}}$ are reported in table 3 .

4.2.2. Determination of $c_{\mathrm{m}}$ and $E_{A}^{e q}$ The concentration of mobile particles $c_{\mathrm{m}}$ is determined from the experimental total $\mathrm{D}$ concentration $c_{\mathrm{D}}^{\exp }$ through equation 15 . In equation $15, c_{\mathrm{D}}$ depends on the knowledge of the trapping energies through $R_{\mathrm{t}, i}\left(T, c_{\mathrm{m}}\right)$ defined in equation 14. The trapping energies are known for both data sets 1 and 2; they are given above in section 4.1 and their concentrations are given in figure 2 . As a consequence, $c_{D}$ can be plotted versus $c_{\mathrm{m}}$ following equation 15, which is done in Figure 4 for various temperatures and fluxes corresponding to the experimental data set 1 and 2 .

In the same way, $E_{A}$ can be derived from $c_{\mathrm{m}}$. Indeed, $E_{A}$ as given by equation 12 depends on $c_{\mathrm{m}}$ and on $c_{\text {surf }}^{\text {eq }}$. Since $c_{\text {surf }}^{\text {eq }}$ was determined in the previous subsection depending on the temperature and the flux, $E_{A}$ can also be plotted against $c_{\mathrm{m}}$ for given temperature and flux, which is also provided in figure 4. It follows that the concentration of mobile particles $c_{\mathrm{m}}$, which is consistent with $c_{\mathrm{D}}^{\mathrm{exp}}$, also determined $E_{A}^{\mathrm{eq}}$. This is shown in figure 4 by dashed the dashed vertical lines connected to the open boxes along each isotherm.

To determine $E_{A}^{\mathrm{eq}}$ with this method, $c_{\mathrm{D}}$ given by equation 15 has to span significantly with $c_{\mathrm{m}}$, i.e. $R_{\mathrm{t}, i}\left(T, c_{\mathrm{m}}\right)<<1$, so the determination of $c_{\mathrm{m}}$ and $E_{A}^{\mathrm{eq}}$ is done with good accuracy. For exposure below 600 $\mathrm{K}, c_{\mathrm{D}}$ does not evolve with $c_{\mathrm{m}}$, i.e. $R_{\mathrm{t}, i}=1$, (figure 4 ) which makes an accurate determination of $E_{A}^{\mathrm{eq}}$ impossible. The value of $E_{A}^{\mathrm{eq}}$ for these temperatures have already been determined in [8]: $1.33 \pm 0.04 \mathrm{eV}$ for the conditions $\left(\Gamma_{\mathrm{D}}^{2}, 500 \mathrm{~K}\right)$ and $1.55 \pm 0.02$ for the conditions $\left(\Gamma_{\mathrm{D}}^{1}, 600 \mathrm{~K}\right)$. As a summary, the temperature and the flux of D atoms determine $c_{\text {surf }}^{\text {eq }}$ (figure 3$) \cdot c_{\text {surf }}^{\text {eq }}$ allows one to plot $E_{A}$ versus $c_{\mathrm{m}}$ for a given temperature and flux. Finally, the value of $c_{\mathrm{m}}$ needed to reach $c_{\mathrm{D}}^{\exp }$ determines the value of $E_{A}^{\mathrm{eq}}$. The determined values of $c_{\mathrm{m}}^{\mathrm{eq}}$ and $E_{A}^{\mathrm{eq}}$ are reported in table 3 .

4.2.3. Fitting of $E_{A}$ Figure 5 displays $E_{A}^{\mathrm{eq}}$ versus $c_{\text {surf }}$ as previously determined with the steady-state model in the above section. Blue circles represent steadystate calculations using experimental conditions from data set 1 , while red squares are for data set 2 . Errorbars are also plotted, they were determined based on the experimental uncertainty on $c_{\mathrm{D}}^{\exp }$.

We applied a non-linear least square regression fit using SciPy's [39, 40] optimize.curve_fit module with the expression:

$E_{A}(\theta)=E_{0}+\Delta E \frac{1}{1+\exp \left(\frac{\theta-a}{b}\right)}$

Agreement with the determined values of $E_{A}^{\mathrm{eq}}$ was found using $E_{0}=1.10 \mathrm{eV}, \Delta E=0.939 \mathrm{eV}, a=0.232$ and $b=0.0683$. The fitted function has been constraint to pass through the points $1.55 \pm 0.02 \mathrm{eV}$ and $1.33 \pm 0.04$ $\mathrm{eV}$ (with the corresponding fluxes) to stay consistent with our previous simulations [8]. Figure 5 includes a plot of $E_{A}(\theta)$ calculated with the fit of equation 18 (the solid black line). At low coverage $(\theta=0.05)$, the steady-state model predicts a decrease of $E_{A}^{\mathrm{eq}}$. This decrease is not included in the function $E_{A}(\theta)$ as recent DFT calculations from Ajmalghan et al [18] report a monotonic behavior of $E_{A}$. In addition, $E_{A}(\theta)$ predicts an $E_{A}$ value around $2.00 \mathrm{eV}$ at low coverage, in good agreement with DFT calculations from Johnson et al. [24] and Heinola et al. [42]. However, knowing the size of DFT calculation cells, it is worth mentioning that extremely low coverage are not accessible by DFT. This issue could be solved by using MD calculations with extremely accurate inter-atomic potentials but it is not the scope of the paper to deal with such calculations, and we do not see any obvious physical process that would decrease $E_{A}$ at low coverage.

\subsection{Test: Rate equations simulations}

To test if the above determined functions $E_{D}(\theta)$ and $E_{A}(\theta)$ can reliably be used in the non-steady-state rate equation code MHIMS, we use them to reproduce the two experiments where data sets 1 and 2 originate from $[20,21]$.

4.3.1. Simulations of experimental data set 1 The depth profiles of data set 1 were already simulated in [36] with the coverage dependent surface energies. The functions $E_{A}(\theta)$ and $E_{D}(\theta)$ shown here are modified to take into account also the data from experimental data set 2 . They differ from the one used in [36] by a maximum of $0.04 \mathrm{eV}$ for $E_{A}(\theta)$ and $0.01 \mathrm{eV}$ for $E_{D}(\theta)$. The updated simulations of these experimental depth profile are presented in figure 6 with the same simulation sequence as described in [36] (the exposure to $\mathrm{D}$ atom lasts $4 \mathrm{~h}$ ).

The small difference in the values of surface energies slightly changes the simulation results but it does not affect the comparison with the experimental 

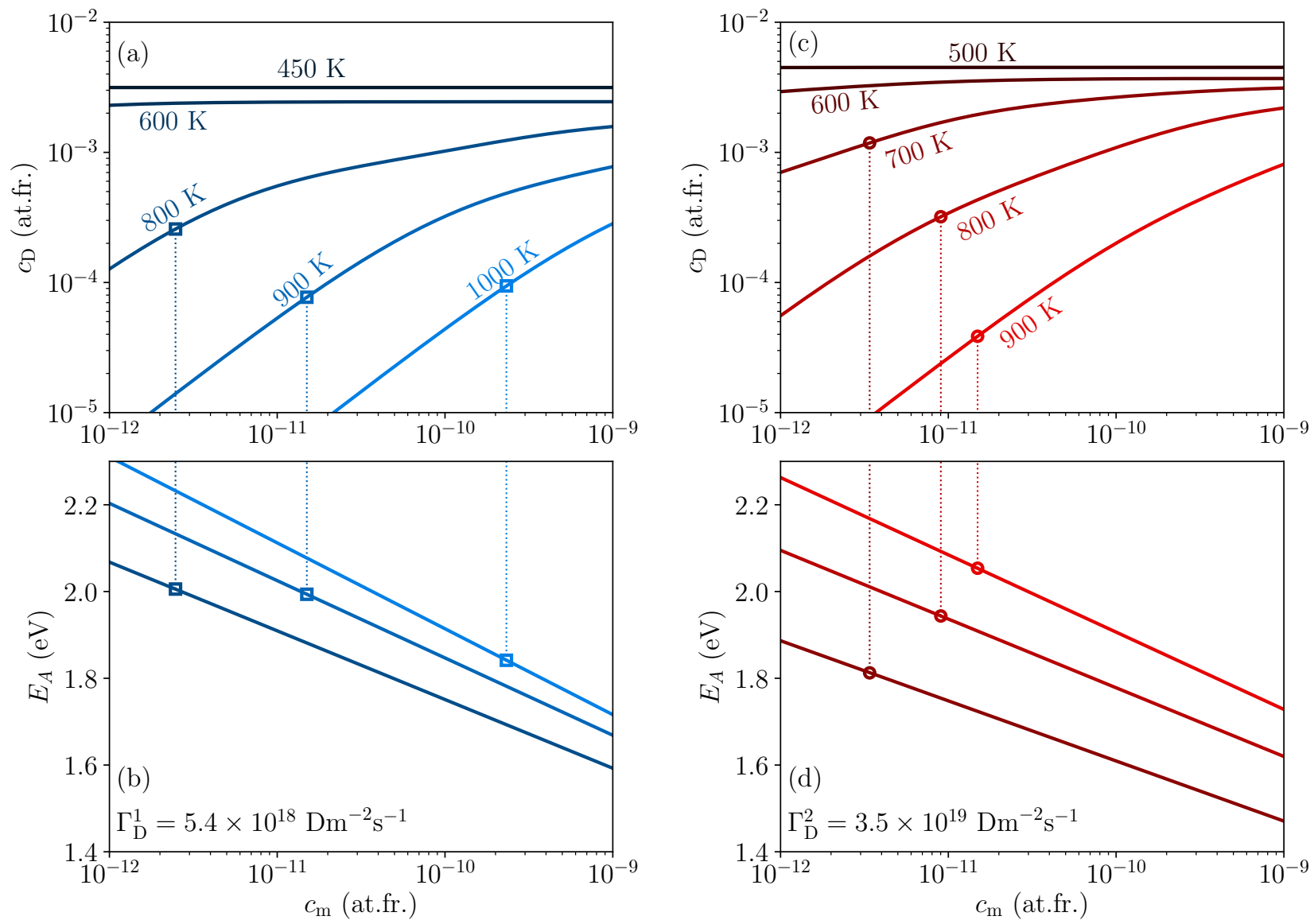

Figure 4: Top: Evolution of $c_{\mathrm{D}}$ with $c_{\mathrm{m}}$ given by equation 15 for the exposure conditions of the experiment 1 [20] (a) and 2 [21] (c). The open symbols show where $c_{\mathrm{D}}$ reached the experimental values reported in table 2: it gives the value of $c_{\mathrm{m}}$ needed to obtained those values. Bottom: Evolution of $E_{A}$ with $c_{\mathrm{m}}$ given by equation 12 for the exposure conditions of experiment 1 [38] (b) and 2 [21] (d). The open symbols give the values of $E_{A}$ needed to have the value of $c_{\mathrm{m}}$ determined in (a) and (c).

depth profiles. At $450 \mathrm{~K}$, the migration depth is still reduced to about $150 \mathrm{~nm}$ below the surface due to a low amount of mobile particles (low temperature and high surface-to-bulk energy barrier). At $600 \mathrm{~K}$, the migration depth extends deeper (about $500 \mathrm{~nm}$ ) but the amount of mobile particles and the temperature are insufficient to fill the damaged layer within the $4 \mathrm{~h}$ of exposure to $\mathrm{D}$ atoms. Above $800 \mathrm{~K}, \mathrm{D}$ reaches till the end of the self-damaged zone. The $\mathrm{D}$ concentration around $1 \mu \mathrm{m}$ in the simulations are higher/equal/lower than the experimental one because the estimated values of $E_{A}$ are above/equal/below in the simulation as compared to the one determined in figure 4 .
4.3.2. Simulations of data set 2 For experimental data set 2, the trap concentrations are taken from the interpolation of the trap concentration used in the simulations of pre-annealed exposure [8] reported in figure 2. Figure 7 shows the comparison between the experimental and the simulated D depth profile after the D exposure. One can see that for exposure temperature above $700 \mathrm{~K}$, the depth profile is not flat but decreases close to the surface. This is resultant from a cool down phase in the simulation, where the temperature decreases gradually to room temperature, taking about $1000 \mathrm{~s}$. As the D flux is shut down at the same time as this temperature decrease starts, a depletion of deuterium occurs near the surface.

In this exposure sequence, the exposure lasts for $3 \mathrm{~h}$ and the damaged layer is $2.5 \mu \mathrm{m}$ thick. For $500 \mathrm{~K}$ 
Table 3: Steady-state value of $E_{D}^{\mathrm{eq}}, \theta^{\mathrm{eq}}=c_{\mathrm{surf}}^{\mathrm{eq}} / n_{\mathrm{surf}}, c_{\mathrm{m}}^{\mathrm{eq}}$ and $E_{A}^{\mathrm{eq}}$ for the experimental conditions considered:

$\Gamma_{\mathrm{D}}^{1}=5.4 \times 10^{18} \mathrm{Dm}^{-2} \mathrm{~s}^{-1}$, $\Gamma_{\mathrm{D}}^{2}=3.5 \times 10^{19} \mathrm{Dm}^{-2} \mathrm{~s}^{-1}$.

The procedure to determine $c_{\mathrm{m}}^{\mathrm{eq}}$ is not applicable for temperature below $600 \mathrm{~K}$ so no value is reported (X). Values for $E_{A}^{\mathrm{eq}}$ at these temperatures are taken from [8].

\begin{tabular}{ccc}
\hline \hline & $\Gamma_{\mathrm{D}}^{1}$ & $E_{D}^{\mathrm{eq}} / \theta^{\mathrm{eq}}-c_{\mathrm{m}}^{\mathrm{eq}} / E_{A}^{\mathrm{eq}}$ \\
\hline $450 \mathrm{~K}$ & $0.66 \mathrm{eV} / 0.330-\mathrm{X} / \mathrm{X}$ & $\Gamma_{\mathrm{D}}^{2}$ \\
$500 \mathrm{~K}$ & - & $0.69 \mathrm{eV} / 0.313-\mathrm{X} / 1.33 \mathrm{eV}[8]$ \\
$600 \mathrm{~K}$ & $0.85 \mathrm{eV} / 0.233-\mathrm{X} / 1.55 \mathrm{eV}[8]$ & $0.81 \mathrm{eV} / 0.252-\mathrm{X} / \mathrm{X}$ \\
$700 \mathrm{~K}$ & - & $0.92 \mathrm{eV} / 0.197-3.40 \times 10^{-12}$ at.fr. $/ 1.81 \mathrm{eV}$ \\
$800 \mathrm{~K}$ & $1.06 \mathrm{eV} / 0.093-2.48 \times 10^{-12}$ at.fr. $/ 2.01 \mathrm{eV}$ & $1.02 \mathrm{eV} / 0.132-9.02 \times 10^{-12}$ at.fr. $/ 1.94 \mathrm{eV}$ \\
$900 \mathrm{~K}$ & $1.09 \mathrm{eV} / 0.028-1.50 \times 10^{-11}$ at.fr. $/ 1.99 \mathrm{eV}$ & $1.08 \mathrm{eV} / 0.059-1.49 \times 10^{-11}$ at.fr. $/ 2.05 \mathrm{eV}$ \\
$1000 \mathrm{~K}$ & $1.10 \mathrm{eV} / 0.008-2.32 \times 10^{-10}$ at.fr. / $1.84 \mathrm{eV}$ & - \\
\hline
\end{tabular}

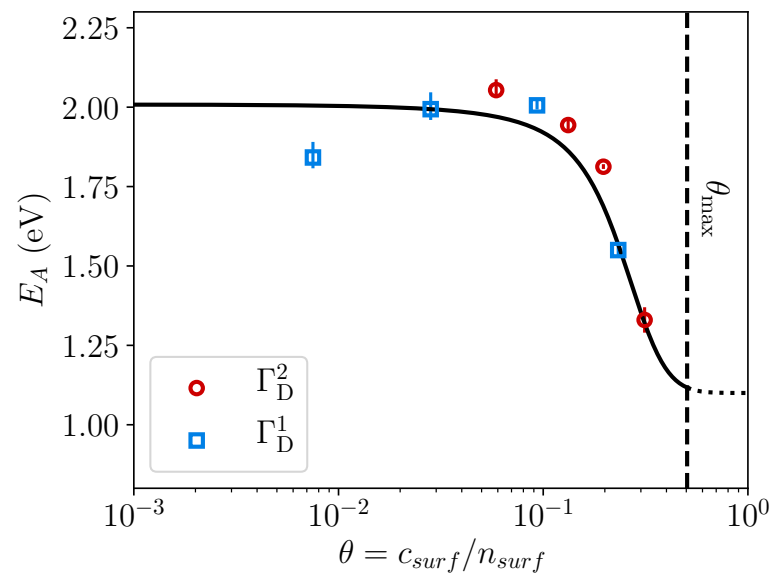

Figure 5: $E_{A}(\theta)$ implemented in MHIMS (solid line) and obtained from the procedure described here (open circles and squares). $\Gamma_{\mathrm{D}}^{1}=5.4 \times 10^{18} \mathrm{Dm}^{-2} \mathrm{~s}^{-1}$ and $\Gamma_{\mathrm{D}}^{2}=3.5 \times 10^{19} \mathrm{Dm}^{-2} \mathrm{~s}^{-1}$. The error bars on the value of $E_{A}$ comes from the experimental error bar of $c_{\mathrm{D}}^{\exp }$.

and $600 \mathrm{~K}$, the D cannot migrate up to the end of the damaged layer.

For $700 \mathrm{~K}$, the concentration of $\mathrm{D}$ is higher (about 2 times) in the simulation as compared to the measured D depth profile since the value of $E_{A}$ in the simulation (solid line in figure 5) is below the one obtained from the steady-state model (open circle in figure 5). This is compensated by the fact that the migration depth is underestimated by the simulation. The possible discrepancy between both simulated and experimental depth profiles could also come from the estimation of the trap concentrations via interpolation from $600 \mathrm{~K}$ and $800 \mathrm{~K}$ data.

For $800 \mathrm{~K}$ and $900 \mathrm{~K}$, the difference between the estimated $E_{A}$ with the steady-state model and the evolution of $E_{A}$ used in MHIMS is about $0.1 \mathrm{eV}$. It follows that the simulated $\mathrm{D}$ concentration is about 2 times higher than the measured one.

4.3.3. Summary of the rate equation simulations The simulations of both experimental data sets reproduce the experimental depth profiles rather well, especially the permeation depth of $\mathrm{D}$ atoms at individual exposure temperatures. The discrepancies have been explained by the deviations between $E_{A}$ given by the steady-state model and $E_{A}(\theta)$ implemented in MHIMS. As the deviations are $0.17 \mathrm{eV}$ for the lowest coverage and below $0.1 \mathrm{eV}$ for the other coverages, the simulated D concentrations are roughly the same order of magnitude as the experimental ones. Thus, one can conclude that the proposed coverage dependent surface energies $E_{D}(\theta)$ and $E_{A}(\theta)$ are adequate when trying to simulate low energy $\mathrm{D}$ atom exposures with the kinetic surface model. This also shows the potential of the steady-state procedure to determine, without extensive simulations, the value of surface energies for arbitrary experimental conditions.

\subsection{Impact on the calculation of the solution energy}

The solution energy $E_{S}$ is defined as the energy change from placing a hydrogen atom from the $\mathrm{H}_{2}$ gas phase into the bulk of $\mathrm{W}$ :

$E_{S}=E_{\mathrm{W}_{\mathrm{bulk}} \mathrm{H}}-E_{\mathrm{W}_{\mathrm{bulk}}}-\frac{1}{2} E_{\mathrm{H}_{2}}$ 

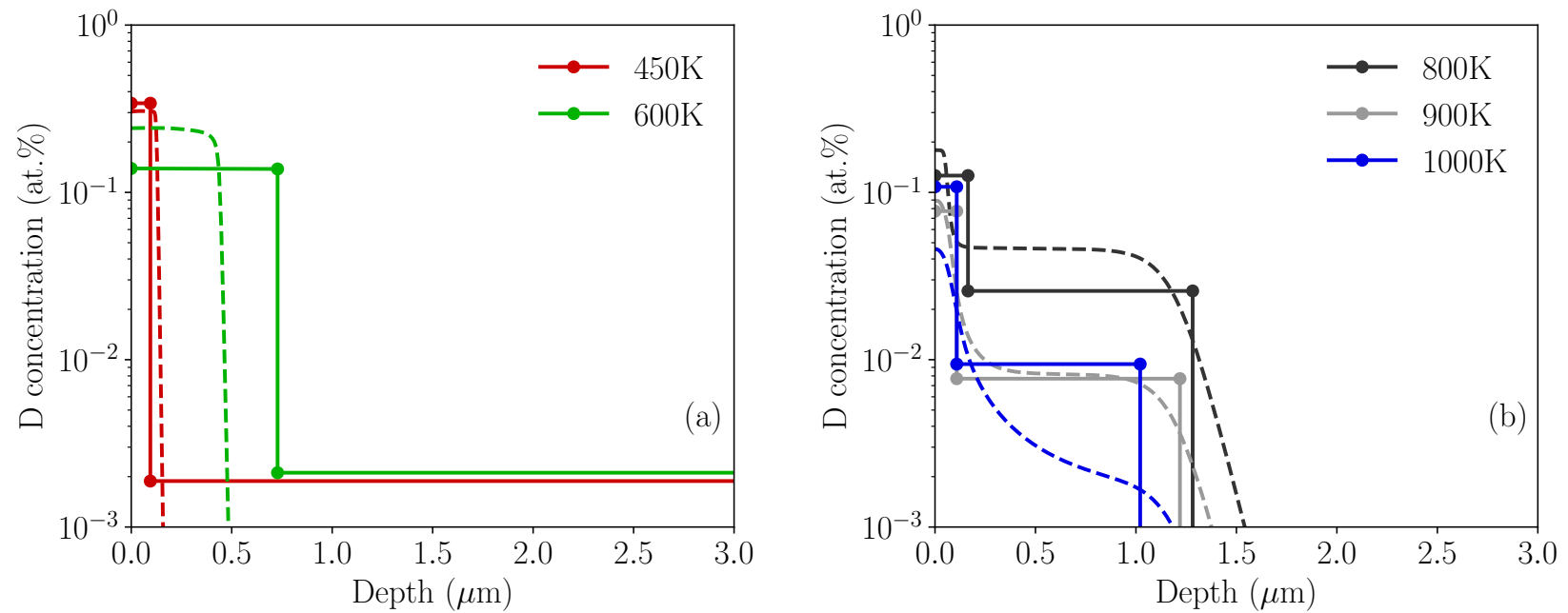

Figure 6: Comparison between experimental D depth profile (solid line) and MHIMS simulations (dashed line) using the coverage dependent surface energies. The exposure conditions are the one of experiment 1 : $\Gamma_{\mathrm{D}}^{1}=5.4 \times 10^{18} \mathrm{Dm}^{-2} \mathrm{~s}^{-1}$. (a) for exposure at $450 \mathrm{~K}$ and $600 \mathrm{~K}$ and (b) for exposure at $800 \mathrm{~K}, 900 \mathrm{~K}$ and 1000 $\mathrm{K}$.
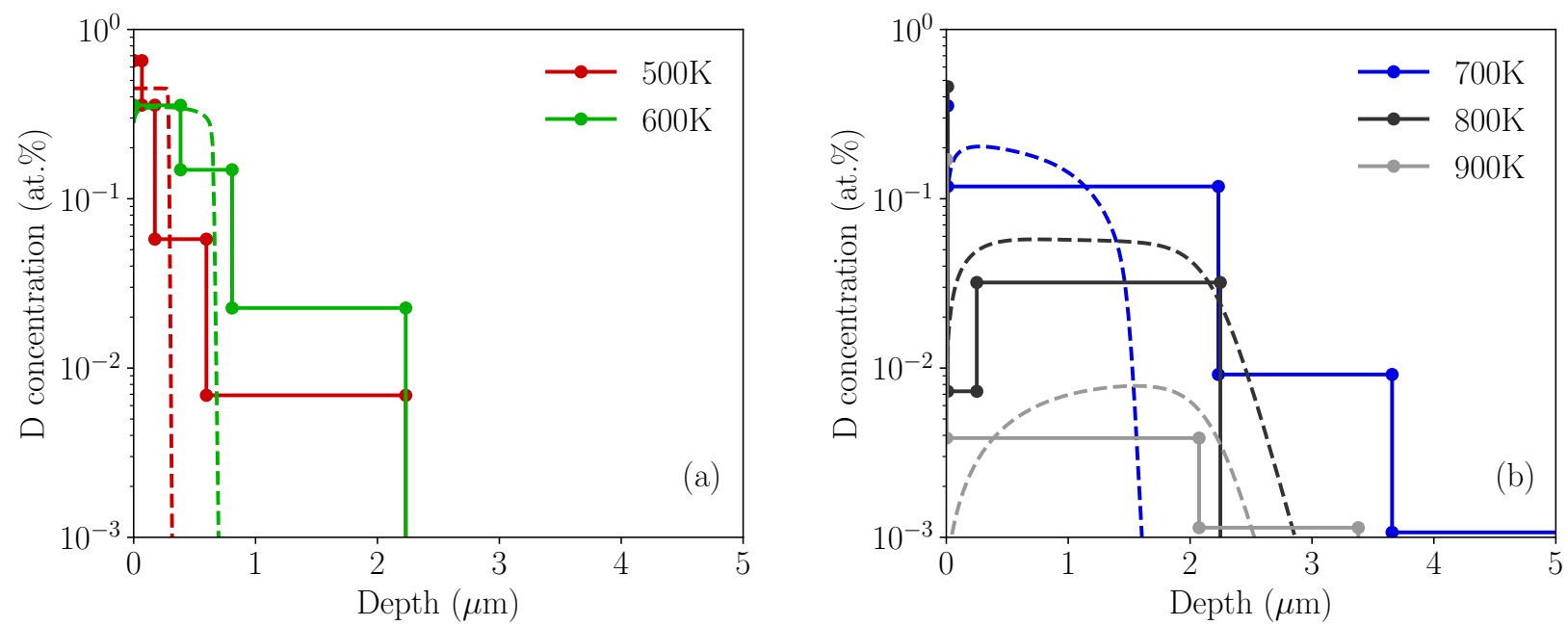

Figure 7: Comparison between experimental D depth profile (solid line) and MHIMS simulations (dashed line) using the coverage dependent surface energies. The exposure conditions are the one of experiment 2 : $\Gamma_{\mathrm{D}}=3.5 \times 10^{19} \mathrm{Dm}^{-2} \mathrm{~s}^{-1}$. (a) for exposure at $500 \mathrm{~K}$ and $600 \mathrm{~K}$ and (b) for exposure at $700 \mathrm{~K}, 800 \mathrm{~K}$ and 900 $\mathrm{K}$.

where $E_{\mathrm{W}_{\text {bulk }} \mathrm{H}}$ is the total energy of W with one $\mathrm{H}$ in interstitial position, $E_{\mathrm{W}_{\text {bulk }}}$ is the total energy of perfect $\mathrm{W}$ and $E_{\mathrm{H}_{2}}$ is the energy of the hydrogen molecules. By definition, $E_{S}$ is independent of the state of the surface. The solution energy can still be calculated considering the full energy path for a hydrogen atom to diffuse from the gas phase to a bulk interstitial site. Let us define $E_{S}^{\text {eff }}$ as in $[12,43]$ :

$E_{S}^{\mathrm{eff}}=E_{A}-E_{D}-E_{R}$
From figure 8, considering the energy profile plotted with the dotted line, $E_{S}^{\text {eff }}$ is obviously the solution energy $E_{S}$. However, this energy profile was recently shown to be distorted in the sub-surface region [18, 32] resulting in the profile plotted with solid line in figure 8. As a consequence, an off-set appears between $E_{S}^{\text {eff }}$ and the solution energy $E_{S}$ (figure 8):

$E_{S}=E_{S}^{\mathrm{eff}}+E_{S}^{\mathrm{off}-\mathrm{set}}$.

The sub-surface distortion (and consequently $E_{S}^{\text {off-set }}$ ) 
depends on several factors, including the orientation of the surface [18], and the surface coverage with hydrogen. This dependence is shown in figure 9 for $E_{A}(\theta)$ and $E_{D}(\theta)$ given in figure 1 and figure 5 , where $E_{S}^{\mathrm{eff}}$ is plotted versus the surface coverage $\theta$.

In MHIMS, the sub-surface region is not

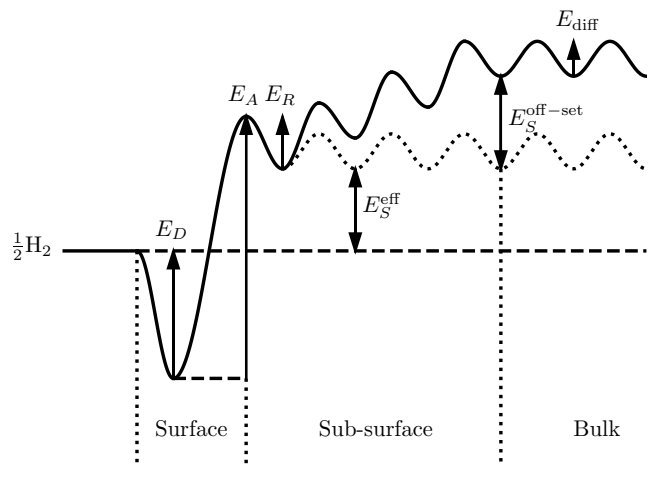

Figure 8: Idealized schematic energy diagram of $\mathrm{H} / \mathrm{W}$ interactions on the surface. The solid line represents the energy path that can be obtained from the NEBDFT calculations. The dashed line correspond to the approximated path leading to $E_{S}^{\mathrm{eff}}$.

considered; it assumes that the asymmetry of the energy wells in the sub-surface is low compared to $E_{A}$ and the latter energy barrier is the limiting step for D uptake from the surface to the bulk. As a consequence, the model in MHIMS considers $E_{S}^{\text {eff }}$, which has to be complemented by $E_{S}^{\text {off-set }}$ in order to meet the experimental value of $E_{S}$ determined by Frauenfelder to be $1.04 \pm 0.17 \mathrm{eV}$ [44]. The highest value of $E_{S}^{\mathrm{eff}}$ is $0.71 \mathrm{eV}$, it occurs at low coverage and is $0.16 \mathrm{eV}$ below the lower value of the solution energy measured by Frauenfelder $\left(E_{S}^{\mathrm{off}-\text { set }} \approx 0.16 \mathrm{eV}\right)$. At high coverage, $E_{S}^{\mathrm{eff}} \approx 0.40-0.50 \mathrm{eV}$ and $E_{S}^{\mathrm{off}-\mathrm{set}} \approx 0.60-0.50 \mathrm{eV}$; this might appear large as compared to DFT results [18] in which $E_{S}^{\text {off-set }}$ does not exceed $0.12 \mathrm{eV}$ on well oriented surfaces. The discrepancy could be explained by the fact that in the present work, we model highly damaged surfaces, which might explain a larger value of $E_{S}^{\text {off-set }}$. Also, one should note that the surface coverage in Frauenfelder's experiment $\left(p_{\mathrm{H}_{2}}=600\right.$ Torr, $T=1100-2400 \mathrm{~K}$ ) leads most likely to extremely low coverages. Such low surface coverages are not reached with the exposure conditions studied here (the highest temperature considered is $1000 \mathrm{~K}$ ) making a direct comparison with Frauenfelder's data complicated.

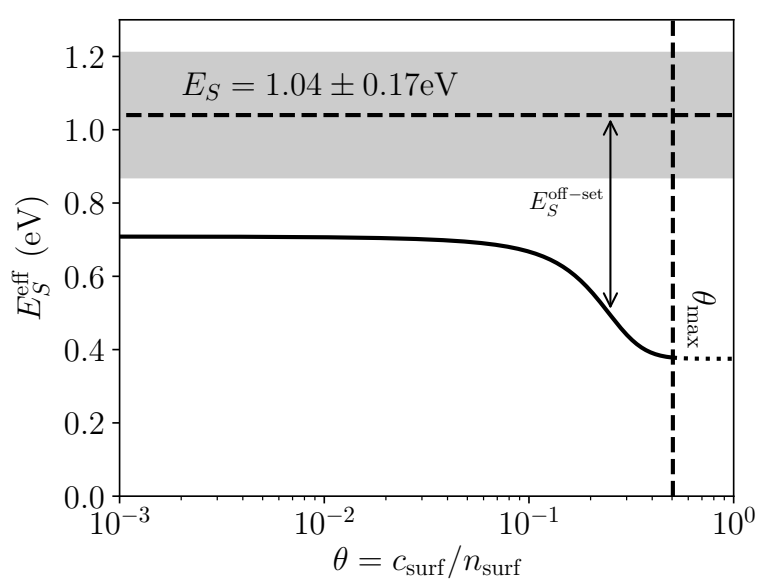

Figure 9: Effective solution energy calculated as $E_{S}^{\mathrm{eff}}=$ $E_{A}(\theta)-E_{D}(\theta)-E_{R}$ as a function of the surface coverage. The vertical line shows the maximal value $\theta_{\max }$ that can be obtained when considering the direct abstraction. The horizontal line is the value measured by Fraunefelder [44] (with the uncertainty of $0.17 \mathrm{eV}$ in grey around the horizontal line).

\section{Extrapolation to various exposure conditions}

In the previous sections, coverage dependent surface energies $E_{D}(\theta)$ and $E_{A}(\theta)$ were determined using experimental data of self-damaged $\mathrm{W}$ exposed to $\mathrm{D}$ atoms at various temperatures (from $450 \mathrm{~K}$ to 1000 $\mathrm{K})$ and two fluxes separated by about one order of magnitude $\left(10^{18}\right.$ and $\left.10^{19} \mathrm{Dm}^{-2} \mathrm{~s}^{-1}\right)$. Now, the steadystate equations presented in section 2.2 are used to calculate the hydrogen isotopes concentration on the surface and in the bulk for various conditions up to what is expected at the strike point in a fusion device. The relevant temperature conditions spans from $450 \mathrm{~K}$ to $1000 \mathrm{~K}$ and the flux range is $10^{18}-10^{24} \mathrm{Dm}^{-2} \mathrm{~s}^{-1}$. In order to simplify this section, we consider the case in which the material is exposed to $0.28 \mathrm{eV} / \mathrm{D}$. Such an exposure regime could correspond to a detached plasma which causes impacts by low energy D atoms upon the $\mathrm{W}$ wall [45]. Changing the impact energy would modify the value of $\sigma_{\text {exc }}[46,47,48]$ and the reflection of atoms [37]. Increasing the energy from $0.28 \mathrm{eV} / \mathrm{D}$ to $2 \mathrm{eV} / \mathrm{D}$ leads to a $\sigma_{\text {exc }}$ increase [46] which would decrease the equilibrium value of $c_{\text {surf }}$ and thus the overall retention. Similarly, the reflection coefficient tends to increase from $0.28 \mathrm{eV} / \mathrm{D}$ to $1 \mathrm{eV} / \mathrm{D}$ and then stays constant up to $5 \mathrm{eV} / \mathrm{D}$ [37] which would also decrease the value of the overall retention.

Above this energy, a significant proportion of the incident atoms is implanted [49]. As shown by Založnik et al [9], even when a low amount of D enters the material via direct implantation, the evolution of 
the retention with exposure temperature is drastically altered. For attached plasma with energy of ions above several tens of $\mathrm{eV}$, the ion are implanted in the material and the surface does not play anymore a significant impact on the retention dynamics [50]. The steadystate model can still be applied, only for the bulk material (with equation 14 and 15). In this case, instead of having a concentration of mobile particles given by 11 , it is proportional to the incident flux and inversely proportional to the diffusion coefficient $[51$, $52]$.

\subsection{Desorption energy $E_{D}$ and Surface coverage $\theta$}

First, we determine the steady-state values of $E_{D}$ and $\theta$ for the considered flux and temperature ranges at which the function $E_{D}(\theta)$ intersects with $E_{D}$ given by equation 9 (cf figure 3 ). The obtained values are reported in figure 10 (a) for $E_{D}$ and (b) for $\theta$. Piazza et al [53] used a Gibb's free energy model to come to similar results estimating the coverage of $\mathrm{H}$ on $\mathrm{W}$. In their case, the thermodynamic model is parametrized by discrete quantum states from DFT and DFPT calculations; results yield a phase diagram over temperature and pressure of $\mathrm{H}_{2}$ instead of whith a flux of atoms that can be found in [54]. However, the end results is basically identical: at low temperature and high pressure (flux), $E_{D}$ is the lowest and $\theta$ reached its maximum value. As the pressure (flux) decreases, $\theta$ decreases and $E_{D}$ increases. Finally, increasing temperature leads to a $\theta$ decrease and so to an increase of $E_{D}$.

One can see that for the small fluxes (below $10^{19}$ $\left.\mathrm{Dm}^{-2} \mathrm{~s}^{-1}\right)$, a temperature of $1000 \mathrm{~K}$ leads to a high value of $E_{D}$ and a very small coverage $\left(\theta<10^{-2}\right)$. In tokamaks, at the strike point, the high incident flux of atoms could heat the W surface up to 1000 $\mathrm{K}$. Considering the highest flux, the coverage would be around 0.2 very far from a bare $W$ surface. In that situation, the $\mathrm{W}$ surface can represent a non-negligible source of recycled $\mathrm{D}_{2}$ molecules (recombination and desorption) for the edge plasma. It also means a higher concentration of mobile particles and so of trapped particles in the bulk material.

\subsection{Absorption energy $E_{A}$ and concentration of mobile particles $c_{\mathrm{m}}$}

Once the value of $\theta$ is determined for given exposure conditions, the corresponding steady-state values of $E_{A}$ and $c_{\mathrm{m}}$ can be obtained using equations 11 and 12 . Both quantities are reported in figure 11 (a) for $E_{A}$ and (b) for $c_{\mathrm{m}}$.

$E_{A}$ shows the same trend as $E_{D}$ : the highest values of $E_{A}$ are obtained for the highest temperatures
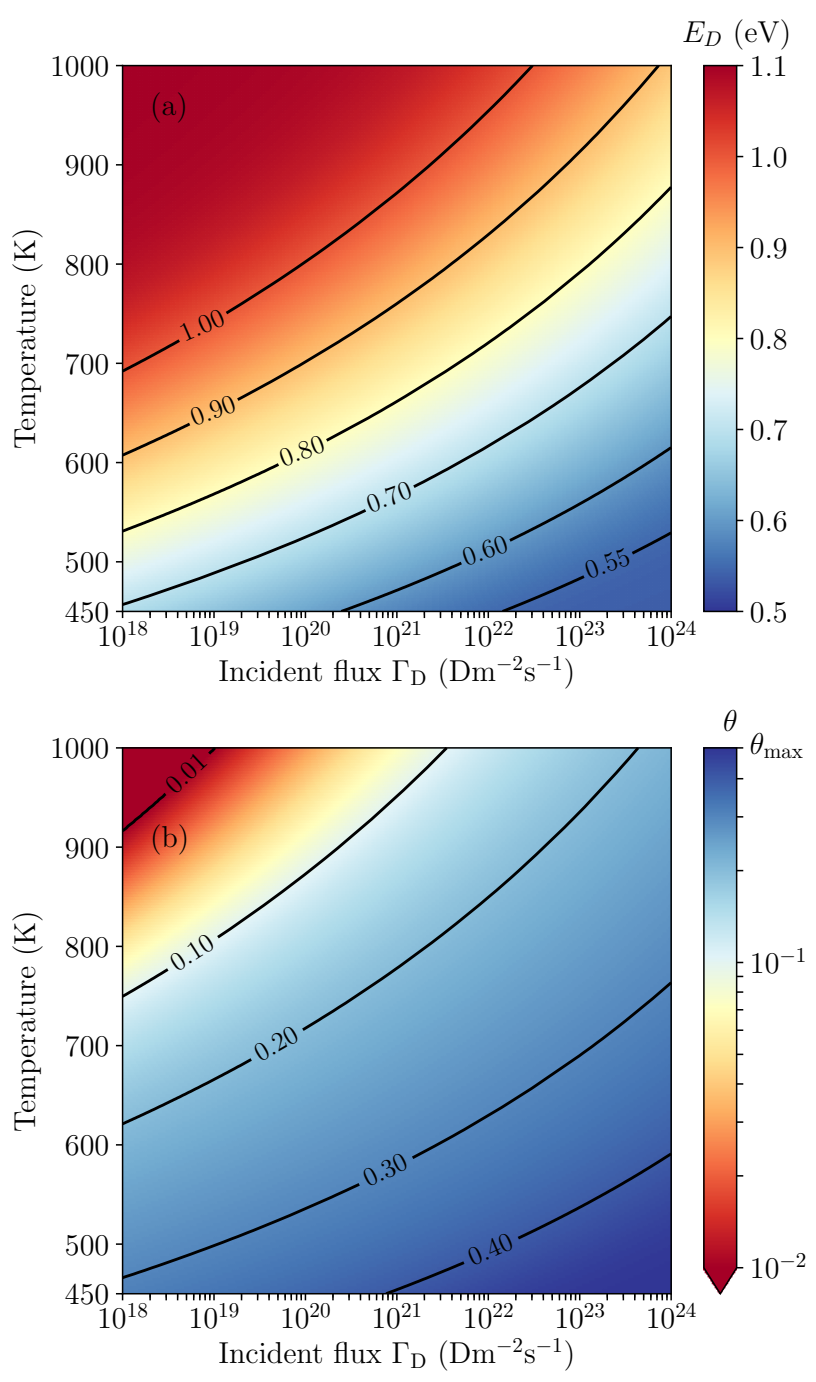

Figure 10: (a) $E_{D}$ at steady-state for atom fluxes ranging from $10^{18}$ to $10^{24} \mathrm{Dm}^{-2} \mathrm{~s}^{-1}$ and for temperatures from $450 \mathrm{~K}$ to $1000 \mathrm{~K}$. (b) $\theta$ at steadystate for the same flux and temperature range. Here, $\theta_{\max }=0.505$. The energy of the atom is considered to be $0.28 \mathrm{eV} / \mathrm{D}$ which means the same values of $\sigma_{\text {exc }}$ and $1-P_{r}$ as the one reported in table 1 .

and for the lowest fluxes.

With constant values of $E_{A}$ and $E_{D}$, the value of $c_{\mathrm{m}}$ would follow an exponential increase with temperature for a given flux. This increase can be seen for the lower right corner of figure 11(b) (high flux, low temperature) for which $E_{A}$ is almost constant. In that region, the isovalue lines have a hyperbolic shape. However, for a given flux below $10^{22} \mathrm{~m}^{-2} \mathrm{~s}^{-1}$, $E_{A}$ evolve significantly from $1.30-1.20 \mathrm{eV}$ to $2.00 \mathrm{eV}$ which induces a more complex shape for $c_{\mathrm{m}}$ that can be seen with the isovalue lines $10^{-11}$ and $10^{-10}$ at.fr.. 

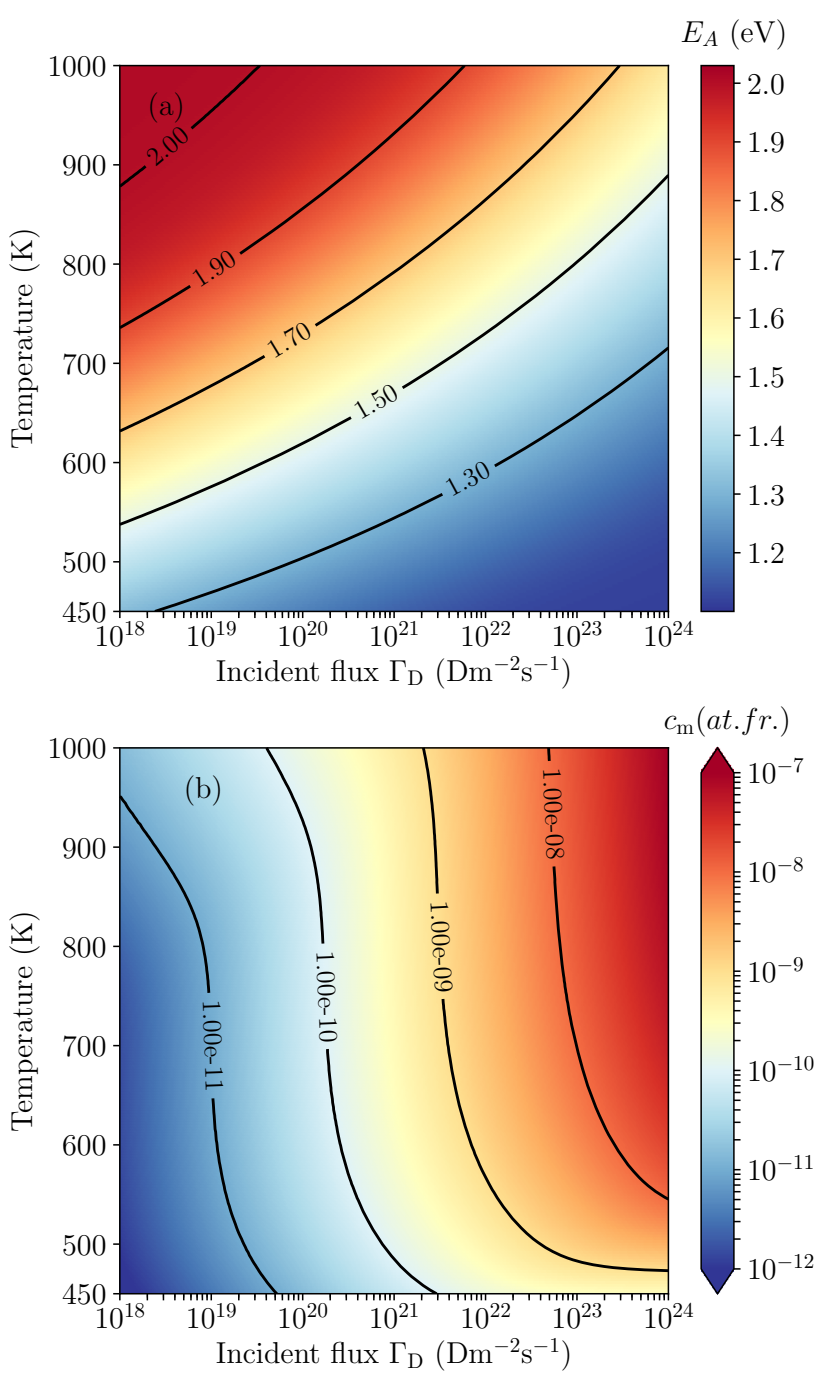

Figure 11: (a) $E_{A}$ at steady-state for atom fluxes ranging from $10^{18}$ to $10^{24} \mathrm{Dm}^{-2} \mathrm{~s}^{-1}$ and for temperatures from $450 \mathrm{~K}$ to $1000 \mathrm{~K}$. (b) $c_{\mathrm{m}}$ at steadystate for the same flux and temperature range.

\subsection{Concentration of trapped particles $c_{\mathrm{t}, i}$}

The value of $c_{\mathrm{m}}$ being known, one can obtain the steady-state concentration of trapped $\mathrm{D}, c_{\mathrm{D}}$, using equations 14 and 15 . The evolution of $c_{\mathrm{D}}$ for the different exposure conditions is reported in figure 12 . For this estimation of $c_{\mathrm{D}}$, we considered the three traps used to simulate the damaged layer of experiment $2(1.65 \mathrm{eV}, 1.85 \mathrm{eV}$ and $2.06 \mathrm{eV})$ and we used the evolution of trap concentrations with temperature given in figure 2 which implements the trap annealing in the damaged layer.

In figure 12 , there is an obvious decrease of $c_{\mathrm{D}}$ with the exposure temperature for a given flux: the detrapping process takes over the trapping process as the dominant mechanism. The peculiar behavior of $c_{\mathrm{m}}$ could have impacted the evolution of $c_{\mathrm{D}}$ but this effect is negligible at least when looking at $c_{\mathrm{D}}$ in logarithmic scale.

One important thing to note is that for all fluxes, exposure below or at $600 \mathrm{~K}$ leads to the quasisaturation of the damaged layer as almost all $R_{\mathrm{t}, i}$ are equal to 1 . Only the trap with the detrapping energies of $1.65 \mathrm{eV}$ might be lower than 1: it is 0.36 at $600 \mathrm{~K}$ for a incident flux of $10^{18} \mathrm{Dm}^{-2} \mathrm{~s}^{-1}$.

More importantly, for fluxes higher than $10^{23}$ $\mathrm{Dm}^{-2} \mathrm{~s}^{-1}$ (typical of strike point fluxes in tokamaks) $c_{\mathrm{D}}$ is above $10^{-3}$ at.fr. up to $1000 \mathrm{~K}$. At $1000 \mathrm{~K}$, the total concentration of traps is $1.7 \times 10^{-3}$ at.fr. (see figure 2) which means that the damaged layer is almost saturated. As a consequence, even in the hottest part of the divertor, where the incident fluxes of particles is the highest, a damaged material can have a high pumping capacity. This means that the increase of the flux, and the subsequent increase of $c_{\mathrm{m}}$, is sufficient to counterbalance the increase of the temperature that would favor the detrapping process.

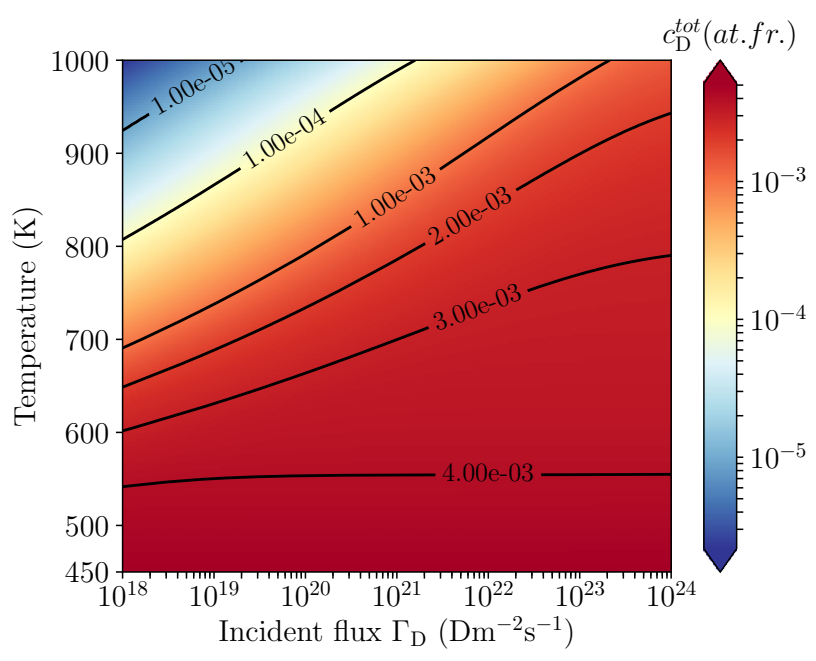

Figure 12: $c_{\mathrm{D}}$ for atom fluxes going from $10^{18}$ to $10^{24}$ $\mathrm{Dm}^{-2} \mathrm{~s}^{-1}$ and for temperature from $450 \mathrm{~K}$ to $1000 \mathrm{~K}$.

\subsection{Migration depth}

In a tokamak situation where the $\mathrm{W}$ material is damaged by neutrons, the thickness of the damaged layer can extend to the full thickness of the material [55]. In that case, it would be interesting to know how far the deuterium atoms can migrate for a given exposure time. To estimate this depth, we can use an analytical model based on an approximation of the profile of mobile particle density as a function of depth. This model was first proposed by Schmid [56] and was used in [8] to determine the migration depth of D. Assuming that the concentration of trapped 
Table 4: Comparison between the migration depth $R_{d}^{10 \%}(t)$ given by the MHIMS simulation and the migration depth $R_{d}(t)$ given by the analytical model of equation 22 . $\Gamma_{\mathrm{D}}^{1}=5.4 \times 10^{18} \mathrm{Dm}^{-2} \mathrm{~s}^{-1}$ and $\Gamma_{\mathrm{D}}^{2}=$ $3.5 \times 10^{19} \mathrm{Dm}^{-2} \mathrm{~s}^{-1}$.

\begin{tabular}{lccc}
\hline \hline & & $\begin{array}{c}R_{d}^{10 \%}(t)(\mu \mathrm{m}) \\
\text { MHIMS }\end{array}$ & $\begin{array}{c}R_{d}(t)(\mu \mathrm{m}) \\
\text { equation } 22\end{array}$ \\
\hline$\Gamma_{\mathrm{D}}^{1}$ & $450 \mathrm{~K}$ & 0.14 & 0.13 \\
$t=4 \mathrm{~h}$ & $600 \mathrm{~K}$ & 0.45 & 0.43 \\
\hline$\Gamma_{\mathrm{D}}^{2}$ & $500 \mathrm{~K}$ & 0.29 & 0.29 \\
$t=3 \mathrm{~h}$ & $600 \mathrm{~K}$ & 0.66 & 0.63 \\
& $700 \mathrm{~K}$ & 1.49 & 1.16
\end{tabular}

deuterium is constant up to the migration depth $R_{d}(t)$, the value of $R_{d}(t)$ after an exposure time $t$ is given by [8]:

$R_{d}(t)=\sqrt{\frac{2 D(T) c_{\mathrm{m}}}{c_{\mathrm{D}}} t}$

This formula is applicable as soon as there is $R_{\mathrm{t}, i}\left(c_{\mathrm{m}}, T\right) \approx 1$ for the dominant traps present in the materials. In that situation, the decrease of $c_{\mathrm{m}}$ with depth (see the simplified profile in $[3,8]$ ) does not really affect the value of $c_{\mathrm{D}}$ up to $R_{d}(t)$.

To validate this equation, one can compare the results of the MHIMS simulations (figure 6 and figure 7) and the results given by equation 22 . To make sense in this validation step, only the cases where $\mathrm{D}$ atoms did not reach the end of the damaged layer are studied, i.e. $450 \mathrm{~K}$ and $600 \mathrm{~K}$ for experiment 1 and $500 \mathrm{~K}, 600 \mathrm{~K}$ and $700 \mathrm{~K}$ for experiment 2 . In those cases, to estimate the $\mathrm{D}$ migration depth, we consider the depth at which $c_{\mathrm{D}}$ reaches $10 \%$ of its maximum value in the simulated profiles in figure 6 and figure 7 . This quantity is called $R_{d}^{10 \%}(t)$. The estimation of $R_{d}(t)$ is calculated considering the maximum D concentration of the simulated profile of figure 6 and figure 7 for $c_{\mathrm{D}}$ and the values of $c_{\mathrm{m}}$ given by equation 11 . The comparison of $R_{d}^{10 \%}(t)$ and $R_{d}(t)$ is given in table 4 . The highest deviation between $R_{d}^{10 \%}(t)$ from the MHIMS simulations and $R_{d}(t)$ given by equation 22 is $22 \%$ for the case $\left(\Gamma_{\mathrm{D}}^{2}, 700 \mathrm{~K}\right)$. For the other cases, the deviation is below $7 \%$ making equation 22 a good estimation of the migration depth of $\mathrm{D}$ in the damaged layer. In all cases, equation 22 underestimates the value of $R_{d}^{10 \%}(t)$. Indeed, the analytical model considers that $c_{\mathrm{D}}$ is constant up to the migration depth and then drops to 0 beyond this depth. In the simulation, $c_{\mathrm{D}}$ decreases more smoothly, whereas the analytical model overestimates $c_{\mathrm{D}}$ at this depth and so underestimates $R_{d}(t)$.

For the conditions $\left(\Gamma_{\mathrm{D}}^{2}, 700 \mathrm{~K}\right)$, during the exposure, the highest value of $c_{\mathrm{m}}$ is $\approx 3.3 \times 10^{-11}$ at.fr. leading to values of $R_{\mathrm{t}, i}\left(c_{\mathrm{m}}, T\right)$ equal to 0.15 , 0.83 and 0.99 for the detrapping energies $1.65 \mathrm{eV}$, $1.85 \mathrm{eV}$ and $2.06 \mathrm{eV}$ respectively. At half the depth of $R_{d}^{10 \%}(t=3 \mathrm{~h}), c_{\mathrm{m}}$ is half this maximum value which leads to values of $R_{\mathrm{t}, i}\left(c_{\mathrm{m}}, T\right)$ equal to $0.08,0.71$ and 0.99 for the detrapping energy $1.65 \mathrm{eV}, 1.85 \mathrm{eV}$ and $2.06 \mathrm{eV}$ respectively. Thus, for 2 of the 3 traps $R_{\mathrm{t}, i}\left(c_{\mathrm{m}}, T\right)$ significantly drops which means that the total concentration of $c_{\mathrm{D}}$ is not entirely flat throughout all the damaged layer. That means we are at the edge of the assumption of the analytical model giving $R_{d}(t)$ and there is a higher deviation between $R_{d}^{10 \%}(t)$ from the MHIMS simulation and $R_{d}(t)$ given by equation 22 for the condition $\left(\Gamma_{\mathrm{D}}^{2}, 700 \mathrm{~K}\right)$.

Considering now the evolution of $c_{\mathrm{D}}$ and $c_{\mathrm{m}}$

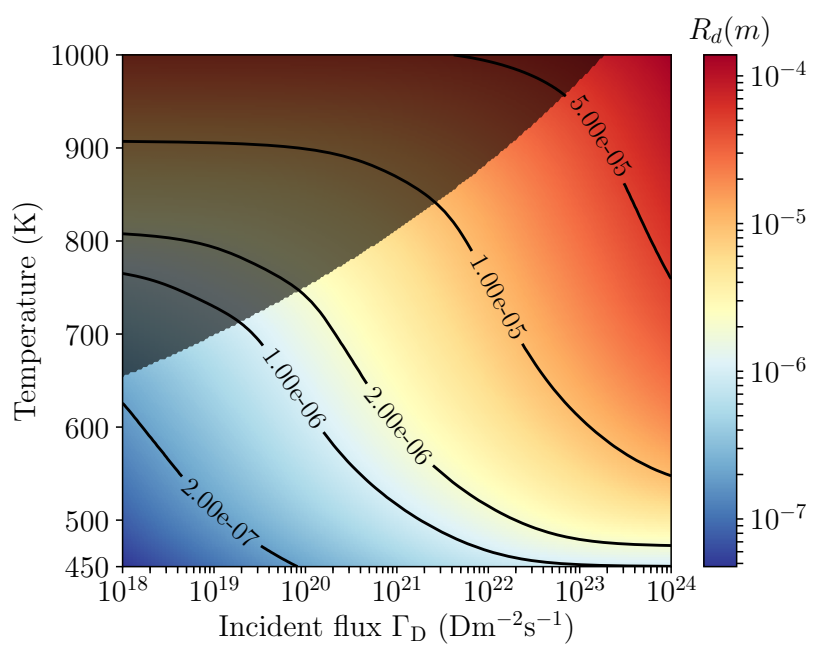

Figure 13: $R_{d}(t)$ given by equation 22 for atom fluxes going from $10^{18}$ to $10^{24} \mathrm{Dm}^{-2} \mathrm{~s}^{-1}$ and for temperatures from $450 \mathrm{~K}$ to $1000 \mathrm{~K}$ with $t=10,000 \mathrm{~s}$. The shadowed region represents the exposure conditions for which $c_{\mathrm{D}} \leq 0.5 \sum_{i} n_{i}$

reported in figure 12 (b) and figure 11 (b) respectively, one can estimate the migration depth of $\mathrm{D}$ atoms for the flux and temperature ranges considered in this section. We consider the case $t=10,000 \mathrm{~s}$ as it is the order of magnitude of the duration of the exposure in the experiment 1 and 2. Assuming that plasma discharges would last $400 \mathrm{~s}$ in ITER, this would correspond to 25 discharges. The evolution of $R_{d}(t)$ for the considered temperature and flux ranges is given in figure 13. As discussed above, the estimation should be trusted in the region where the traps are almost saturated $\left(R_{\mathrm{t}, i}\left(c_{\mathrm{m}}, T\right) \approx 1\right)$. Thus, the region for 
which $c_{\mathrm{D}} \leq 0.5 \sum_{i} n_{i}$ should not be fully trusted as it corresponds to the previous case $\left(\Gamma_{\mathrm{D}}^{2}, 700 \mathrm{~K}\right)$. This region is shadowed in figure 13 .

$R_{d}(t)$ increases with increasing temperature and fluxes. This is expected as $c_{\mathrm{m}}$ globally increases with both $T$ and $\Gamma_{\mathrm{D}}$. In figure 13 , the isoline for $R_{d}(t)=1 \mu \mathrm{m}$ and $R_{d}(t)=2 \mu \mathrm{m}$ are shown. Those depths are the thickness of damaged layer induced by irradiations with $10 \mathrm{MeV}$ and $20 \mathrm{MeV} \mathrm{W}$ ions. Thus, figure 13 gives an estimation for which conditions of $10,000 \mathrm{~s}$ exposure leads to the filling of the damaged layer. For instance, for the flux of experiment $1 \Gamma_{\mathrm{D}}^{1}$, in which $10 \mathrm{MeV} \mathrm{W}$ ions have been used, the analytical model of $R_{d}(t)$ estimates that a $1 \mu \mathrm{m}$ damaged layer would be filled for temperatures above about $750 \mathrm{~K}$. For the flux of experiment $2 \Gamma_{\mathrm{D}}^{2}$, in which $20 \mathrm{MeV}$ is the highest energy of the $\mathrm{W}$ ions, equation 22 estimates that the $2 \mu \mathrm{m}$ damaged layer is filled for temperatures above $800 \mathrm{~K}$. If one considers now an ITER case where the incident flux on the $\mathrm{W}$ target is above $10^{23} \mathrm{Dm}^{-2} \mathrm{~s}^{-1}$ and the temperature is around $1000 \mathrm{~K}$, a $10,000 \mathrm{~s}$ exposure to $0.28 \mathrm{eV} / \mathrm{D}$ leads to D migration up to $50 \mu \mathrm{m}$. In [6], MHIMS simulations shows that after $20 \times 400 \mathrm{~s}$ exposure to $25 \mathrm{eV} / \mathrm{D}$ with an incident flux of $1 \times 10^{24} \mathrm{Dm}^{-2} \mathrm{~s}^{-1}$ at about $1000 \mathrm{~K}$, the migration depth is about $200 \mu \mathrm{m}$ for a damaged material (i.e. with the same three detrapping energies as here and comparable trap concentrations). With the same exposure conditions but with a flux of atoms instead of a flux of implanted ions, the migration depth given by equation 22 is about $100 \mu \mathrm{m}$ : for these conditions, an ion flux of $25 \mathrm{eV} / \mathrm{D}$ and an atom flux of $0.28 \mathrm{eV} / \mathrm{D}$ are equivalent in terms of retention and migration depth.

\section{Conclusion}

In this paper, a method based on steady-state analysis is used to link the surface and trapping properties of hydrogen in W. This method can be used to determine surface energies from bulk D concentrations if the exposure conditions and trapping properties (detrapping energies and concentrations) are known.

Using this method, we determine the dependence of the desorption energy $E_{D}$ and the absorption energy (the surface into the bulk) $E_{A}$ on hydrogen coverage. For both energies the dependence is similar: they increase as coverage decreases which is in agreement with DFT calculations [17, 18].

The coverage dependent surface energies were implemented in the code MHIMS which is used to simulate the experiments of self-damaged $\mathrm{W}$ exposed to $0.28 \mathrm{eV} / \mathrm{D}$ atoms between $450 \mathrm{~K}$ and $1000 \mathrm{~K}$ [20, 21]. The simulations show good agreement with experiments which validates the new implementation of coverage dependent surface energies as well as the steady-state model used to calculate them.

Finally, the steady-state equations derived in this paper and the coverage dependent surface energies are used to estimate what would be the surface energies, surface concentration, bulk D concentrations and D migration for various exposure conditions. The flux range considered goes from $10^{18}$ to $10^{24} \mathrm{Dm}^{24} \mathrm{~s}^{-1}$ and the temperature range goes from $450 \mathrm{~K}$ to $1000 \mathrm{~K}$. This ranges are sufficient to cover cases from laboratory experiment to tokamak conditions. As the energy of the atoms in this work is low $(0.28 \mathrm{eV} / \mathrm{D})$, the models/simulations herein are relevant for detached plasma conditions, but consistent models could also be used for ion implantation and attached plasma. The model can be used to determine for which conditions a damaged layer created by $10 \mathrm{MeV} \mathrm{W}$ ions $(\approx 1 \mu \mathrm{m}$ thick) or $20 \mathrm{MeV} \mathrm{W}$ ions ( $\approx 2 \mu \mathrm{m}$ thick) can be filled by $0.28 \mathrm{eV} / \mathrm{D}$ atoms. However, this model is not limited to shallow layers with displacement damage, but can be also used for tungsten with displacement damaged throughout as it is expected for neutron irradiated tungsten plasma facing materials. It can therefore be used to estimate the fuel retention and penetration depth in ITER relevant cases.

\section{Acknowledgments}

All plots in this work were generated with Matplotlib [57].

Work performed under EUROfusion WP PFC. This work has been carried out within the framework of the EUROfusion Consortium and has received funding from the Euratom research and training programme 2014-2018 and 2019-2020 under grant agreement No 633053. The views and opinions expressed herein do not necessarily reflect those of the European Commission.

The project leading to this publication has received funding from Excellence Initiative of Aix-Marseille University - $A^{*}$ Midex, A French "Investissements d'Avenir" programme.

This work has received funding from the French National Research Agency (Grant No. ANR-18-CE050012).

The authors acknowledge the support from the Slovenian Research Agency (research core funding No. P20405). 


\section{Appendices}

\section{A. Justification of $\left(\frac{\partial c_{\mathrm{m}}}{\partial x}\right)_{x=0} \approx 0$}

We consider the case where a $\mathrm{W}$ material is exposed to low energy D atoms. As explained in [8], the profile of mobile particles can be approximated with a triangular shape (see figure 3 in [8]) up to the migration depth $\Delta x: c_{\mathrm{m}}(x=0)=c_{\mathrm{m}}^{0}$ and $c_{\mathrm{m}}(x=\Delta x)=0 . \quad$ The evolution of $c_{\mathrm{m}}(x=0)$ is given, in equation 4 , by the flux balance between the flux that brings mobile particles in $x=0, \phi_{\text {surf } \rightarrow \text { bulk }}$, and the fluxes that drive mobile particles away from $x=0, \phi_{\text {bulk } \rightarrow \text { bulk }}$ and $\phi_{\text {diff }}$. At steady-state, there is:

$\phi_{\text {surf } \rightarrow \text { bulk }}-\phi_{\text {bulk } \rightarrow \text { surf }}-\phi_{\text {diff }}=0$

To justify that $\left(\frac{\partial c_{\mathrm{m}}}{\partial t}\right)_{x=0} \approx 0$, we compare both fluxes that drives away particles from $x=0$ and we consider for that the simple triangular-shape profiles of $c_{\mathrm{m}}$ : $\left(\frac{\partial c_{\mathrm{m}}}{\partial x}\right)_{x=0}=\frac{c_{\mathrm{m}}^{0}}{\Delta x}$. The flux balance becomes then:

$-D \frac{c_{\mathrm{m}}^{0}}{\Delta x}-\nu_{\mathrm{bs}} c_{\mathrm{m}}^{0}(1-\theta)+\phi_{\mathrm{surf} \rightarrow \mathrm{bulk}}=0$

which leads to:

$-c_{\mathrm{m}}^{0}\left(\frac{D}{\Delta x}+\nu_{\mathrm{bs}}(1-\theta)\right)+\phi_{\text {surf } \rightarrow \text { bulk }}=0$.

According to table $1, \nu_{\mathrm{bs}}=\nu_{0} \lambda_{\mathrm{abs}} \exp \left(-\frac{E_{R}}{k_{\mathrm{B}} T}\right)$ and according to [22], $D \approx \nu_{0} \lambda^{2} \exp \left(-\frac{E_{D}}{k_{\mathrm{B}} T}\right)$ (with the value of $\nu_{0}$ and $\lambda$ in table 1 ). We choose $E_{R}=E_{D}$ and the order of magnitude of $\lambda$ and $\lambda_{\text {abs }}$ are the same (hundreds of picometers) which means $\lambda_{\text {abs }} \approx \lambda$. Thus, $c_{\mathrm{m}}^{0} \lambda \nu_{0} \exp \left(-\frac{-E_{R}}{k_{\mathrm{R}} T}\right) \approx \frac{\phi_{\text {bulk } \rightarrow \text { surf }}}{1-\theta}$ and the balance flux in steady-state can then simplified as:

$-\frac{\phi_{\text {bulk } \rightarrow \text { surf }}}{1-\theta}\left(\frac{\lambda}{\Delta x}+(1-\theta)\right)+\phi_{\text {surf } \rightarrow \text { bulk }}=0$

We then have to compare $\frac{\lambda}{\Delta x}$ and $(1-\theta)$. The maximum coverage during the low atom exposure considered here is give by equation 10 and $\theta_{\max } \approx 0.5$ : we can approximate $(1-\theta) \approx 1$. On the other hand, the migration depth in the considered cases is about $1 \mu \mathrm{m}$ : $\frac{\lambda}{\Delta x} \approx \frac{10^{-10}}{10^{-6}}=10^{-4}$ which means that $\frac{\lambda}{\Delta x}<<(1-\theta)$ and the flux balance can be simplified as:

$-\phi_{\text {bulk } \rightarrow \text { surf }}+\phi_{\text {surf } \rightarrow \text { bulk }}=0$.

This means that the diffusion flux $\phi_{\text {diff }}$ can be neglected in the steady-state equation if the migration depth is several order of magnitude higher than the distance between two interstitial sites when the maximum concentration $c_{\mathrm{m}}^{0}$ is right at the surface. It is worth noting that this assumption is not valid at the very beginning of the exposure when the diffusion depth is of the order of few nanometers.

\section{B. Steady-state of $c_{\mathrm{t}, i}$ with fill-dependent detrapping energies}

Considering a material in which there are several trapping sites $i$ for hydrogen $(\mathrm{H})$. The concentration of trapping site $i$ is $n_{i}\left(\mathrm{~m}^{3}\right.$, see table 1$)$. In the filldependent detrapping energies model, each trapping site can contain up to $l_{i}$ hydrogen. The concentration of trapping sites $i$ containing $k(\mathrm{H})$ is called $n_{i}^{k}$. Thus, the total concentration of trapped hydrogen $c_{t}$ is:

$c_{\mathrm{t}}=\sum_{i} c_{\mathrm{t}, i}=\sum_{i} \sum_{k=1}^{l_{i}} k n_{i}^{k}$

The equations describing the temporal evolution of each $n_{i}^{k}$ can be found in $[27,28]$. Here, we present the steady-state equation giving the total concentration of trapped hydrogen as function of the local concentration of mobile hydrogen $\left(c_{m}\right)$ and the detrapping and trapping rate constants, respectively $\nu_{i}(T)$ and $\nu_{\mathrm{m}}(T)$ (expression in table 1). Once the steady-state is reached, one can write:

$n_{i}^{k}=R_{\mathrm{t}, i}^{k}\left(T, c_{\mathrm{m}}\right) n_{i}$

Here, $R_{\mathrm{t}, i}\left(T, c_{\mathrm{m}}\right)^{k}$ has the same meaning as the one presented in equation 14: it gives the proportion of trapping site $i$ filling with $k$ hydrogen. However, its expression is a bit different as each filling level depend on the lower and upper one. From the equation of the model and the steady-state ratio $n_{i}^{k} / n_{i}^{k-1}, n_{i}^{k} / n_{i}^{0}$ and $n_{i}^{l_{i}} / n_{i}^{k}$ presented in [28], one get the equations 30,31 and 32 for $R_{\mathrm{t}, i}^{k}$.

In its standard version (equation 14), $R_{\mathrm{t}, i}$ increases when trapping becomes predominant over detrapping which is characterized by the presence of $\frac{\nu_{i}(T)}{\nu_{\mathrm{m}}(T) c_{\mathrm{m}}}$ in the denominator. In the contrary, the inverse fraction, $\frac{\nu_{\mathrm{m}}(T) c_{\mathrm{m}}}{\nu_{i}(T)}$ would characterizes the predominance of detrapping over trapping. In the filllevel dependent detrapping energies, what increases the amount of particles trapped in each level $k$ is the trapping in filling level bellow it and the detrapping from level above it: in the denominator of $R_{\mathrm{t}, i}^{k}\left(T, c_{\mathrm{m}}\right)$, there are $\frac{\nu_{q}(T)}{\nu_{\mathrm{m}}(T) c_{\mathrm{m}}}$ for all levels $q<k$ and $\frac{\nu_{\mathrm{m}}(T) c_{\mathrm{m}}}{\nu_{q}(T)}$ for all levels $q>k$. As they have to be stacked from level $q$ to $k$, they are multiply which explains the products in the formula of $R_{\mathrm{t}, i}^{k}\left(T, c_{\mathrm{m}}\right)$.

As for the standard model, using the formula of $R_{\mathrm{t}, i}^{k}\left(T, c_{\mathrm{m}}\right)$, one can obtain the concentration of trapped particle for a given temperature and concentration of mobile particles as:

$c_{\mathrm{t}}=\sum_{i}\left(\sum_{k=1}^{l_{i}} k R_{\mathrm{t}, i}^{k}\left(T, c_{\mathrm{m}}\right)\right) n_{i}$

The method described in 2.2 can then be applied exactly in the same way as with the standard model. 


$$
\begin{aligned}
& k=0, R_{\mathrm{t}, i}^{k}\left(T, c_{\mathrm{m}}\right) \quad=\frac{1}{1+\sum_{q=1}^{l_{i}} \frac{\left(\nu_{\mathrm{m}}(T) c_{\mathrm{m}}\right)^{q}}{\Pi_{j=1}^{q} \nu_{j}(T)}} \\
& 1 \leq k<l_{i}, R_{\mathrm{t}, i}^{k}\left(T, c_{\mathrm{m}}\right)= \\
& k=l_{i}, R_{\mathrm{t}, i}^{k}\left(T, c_{\mathrm{m}}\right) \quad=\frac{1}{1+\sum_{q=0}^{k-1} \frac{\Pi_{j=q+1}^{k} \nu_{j}(T)}{\left(\nu_{\mathrm{m}}(T) c_{\mathrm{m}}\right)^{k-q}}+\sum_{q=k+1}^{l_{i}} \frac{\left(\nu_{\mathrm{m}}(T) c_{\mathrm{m}}\right)^{q-k}}{\Pi_{j=k+1}^{q} \nu_{j}(T)}} \\
& 1+\sum_{q=0}^{l_{i}-1} \frac{1}{\left(\Pi_{j=q+1}^{l_{i}-q} \nu_{j}(T)\right.}
\end{aligned}
$$

\section{Detail of the experimental data set used}

\section{C.1. Data from set 1}

In the experiment from which this set is taken, W samples are simultaneously exposed to $0.28 \mathrm{eV} / \mathrm{D}$ atoms and to $10.8 \mathrm{MeV} \mathrm{W}$ ions at temperatures of $450 \mathrm{~K}, 600 \mathrm{~K}, 800 \mathrm{~K}, 900 \mathrm{~K}$ and $1000 \mathrm{~K}$. With such W energy, the displacement-damaged layer extends from the surface to a depth of $1.0-1.5 \mu \mathrm{m}$. The atom flux is $\Gamma_{\mathrm{D}}^{1}=5.4 \times 10^{18} \mathrm{Dm}^{-2} \mathrm{~s}^{-1}$, the exposure time is 4 hours and the damage dose is calculated to be 0.47 $\mathrm{dpa}_{\mathrm{KP}}$ (more details can be found in [20]). After this first exposure to $\mathrm{D}$ atoms, the $\mathrm{D}$ depth profiles are measured with nuclear reaction analysis (NRA). These depth profiles are used for the steady-state analysis. In this experiment, there is a few minutes delay between the end of the D exposure and the cooling to room temperature, meaning the sample temperature starts to fall before the D atom flux is turned off. In our previous simulations work [36], it has been shown that this delay affects the D concentration in the first hundreds of nanometers for exposure temperatures of $800 \mathrm{~K}, 900 \mathrm{~K}$ and $1000 \mathrm{~K}$. Thus, for the mentioned exposure temperatures, the steady-state experimental D concentration $c_{\mathrm{D}}^{\mathrm{exp}}$ are defined at a depth of $1 \mu \mathrm{m}$.

For the steady-state analysis and for the MHIMS simulations, we need relevant trapping parameters to describe the trapping sites created by the $\mathrm{W}$ implantation, which have been already obtained in [36]: the damaged layer is simulated with 2 traps with detrapping energies of $1.83 \mathrm{eV}$ and $2.10 \mathrm{eV}$.

\section{C.2. Data from set 2}

In [21], two experiments are presented with different $\mathrm{W}$ damaging procedure and D exposures. Both experiments meant to investigate the effect of temperature on D retention in the displacementdamage layer.

The point of the first one is to check the effect of temperature on $\mathrm{D}$ retention during the $\mathrm{D}$ exposure and is thus called in [21] exposure. There, W samples are first damaged at room temperature by $\mathrm{W}$ ions at energies of $20,8,4$ and $2 \mathrm{MeV}$ in order to obtain a homogeneous damage profile of 0.45 dpaKP down to 2.5 $\mu \mathrm{m}$. The damaged samples are then exposed to 0.28 $\mathrm{eV} / \mathrm{D}$ atom at temperatures of $500 \mathrm{~K}, 600 \mathrm{~K}, 700 \mathrm{~K}$, $800 \mathrm{~K}$ and $900 \mathrm{~K}$ with an atom flux of $\Gamma_{\mathrm{D}}^{2}=3.5 \times 10^{19}$ $\mathrm{Dm}^{-2} \mathrm{~s}^{-1}$. The three hour exposure with the used D flux yields a D fluence of $3.8 \times 10^{23} \mathrm{Dm}^{-2}$. After the D atom exposure, the NRA D depth profile is measured. The distribution of $\mathrm{D}$ is homogeneous in the damaged layer up to $2 \mu \mathrm{m}$ when the exposure temperature is above $700 \mathrm{~K}$. For the steady-state analysis, we thus use the value of $c_{\mathrm{D}}^{\exp } 2 \mu \mathrm{m}$ below the surface. For temperatures of $500 \mathrm{~K}$ and $600 \mathrm{~K}$, an exposure of $3 \mathrm{~h}$ is not enough to saturate all the damaged layer. Thus, we use maximal measured deuterium concentration in the damaged layer for the steady-state analysis as the concentration of D is locally at steady-state close enough to the surface. The values of D concentrations for the experimental set 2 are reported in table 2 .

The purpose of the second experiments presented in [21] is to investigate the effect of pre-annealing of the damaged layer before the D exposure. It is thus called in [21] pre-annealing. In this experiment, W samples are damaged at room temperature by $20 \mathrm{MeV}$ W ions up do a dose of $0.25 \mathrm{dpa}$. With such an energy, the dpa profile is peaked around $1.5 \mu \mathrm{m}$ and extends up to 2.5 $\mu \mathrm{m}[21,58]$. The samples are then annealed for $1 \mathrm{~h}$ at a temperature of $600 \mathrm{~K}, 800 \mathrm{~K}, 1000 \mathrm{~K}$ and $1200 \mathrm{~K}$ (one sample is left un-annealed). The annealing is followed by exposure to $0.28 \mathrm{eV} / \mathrm{D}$ atoms with a flux of $2.6 \times 10^{19}$ $\mathrm{Dm}^{-2} \mathrm{~s}^{-1}$ at $500 \mathrm{~K}$ for $144 \mathrm{~h}$. The $\mathrm{D}$ depth profile is measured with NRA after the D atom exposure. More detail on the results of this pre-annealing experiment can be found in [58].

It has been shown by Ogordnikova et al [59] that the deuterium retention in self-damaged $\mathrm{W}$ saturates at higher damage level. The tungsten fluence stated in [59] for such a saturation converts to 0.1 dpaKP. This statement, combined with the experimental fact that the $\mathrm{D}$ maximum concentration measured in exposure and pre-annealing experiments is the same when the exposure temperature is $500 \mathrm{~K}$, makes use think that the trap types and trap concentrations produced in both $\mathrm{W}$ irradiation sequences are the same. In this study, we are using the data from 
exposure to determine the evolution of the coverage dependent energies. However, we need relevant trapping parameters to do so. In a previous studies [8], we determined the trapping parameters for the preannealing experiments: the damaged layer can be simulated with 3 traps with detrapping energies of 1.65 $\mathrm{eV}, 1.85 \mathrm{eV}$ and $2.06 \mathrm{eV}$ and the concentration of each trap varies with the annealing temperature. As the amount and nature of traps created by both damaging sequence are similar, at least for exposure at $500 \mathrm{~K}$, one can use these trapping parameters for the exposure at $500 \mathrm{~K}$ of the exposure experiments. For the other exposure temperatures in the exposure experiments, we consider that the amount of traps after exposing to $\mathrm{D}$ at a temperature $\mathrm{T}$ is similar to the amount of traps after annealing at this temperature. It is a simplification that help us to use the concentration of traps obtained from the simulations of pre-annealing experiments to simulate the damaged layer of exposure experiments. Thus, for exposure temperatures of $600 \mathrm{~K}$ and $800 \mathrm{~K}$, we use the concentration of traps determined in [8] and for exposure temperatures of 700 $\mathrm{K}$ and $900 \mathrm{~K}$, we interpolate the trap concentrations obtained for $500 \mathrm{~K}, 600 \mathrm{~K}, 800 \mathrm{~K}$ and $1000 \mathrm{~K}$ using python SCIPY package [39].

\section{References}

[1] C. Grisolia. Plasma wall interaction during long pulse operation in tore supra. Journal of Nuclear Materials, 266-269:146 - 152, 1999.

[2] K. Schmid, V. Rieger, and A. Manhard. Comparison of hydrogen retention in $\mathrm{w}$ and $\mathrm{w} /$ ta alloys. Journal of Nuclear Materials, 426(1):247 - 253, 2012.

[3] K Schmid. Diffusion-trapping modelling of hydrogen recycling in tungsten under ELM-like heat loads. Physica Scripta, T167:014025, jan 2016.

[4] K Schmid, J Bauer, T Schwarz-Selinger, S Markelj, U v Toussaint, A Manhard, and W Jacob. Recent progress in the understanding of $\mathrm{h}$ transport and trapping in w. Physica Scripta, 2017(T170):014037, 2017.

[5] E.A. Hodille, X. Bonnin, R. Bisson, T. Angot, C.S. Becquart, J.M. Layet, and C. Grisolia. Macroscopic rate equation modeling of trapping/detrapping of hydrogen isotopes in tungsten materials. Journal of Nuclear Materials, 467:424 - 431, 2015.

[6] E A Hodille, E Bernard, S Markelj, J Mougenot, C S Becquart, R Bisson, and C Grisolia. Estimation of the tritium retention in ITER tungsten divertor target using macroscopic rate equations simulations. Physica Scripta, 2017(T170):014033, 2017.

[7] M. H. J. 't Hoen, M. Mayer, A. W. Kleyn, and P. A. Zeijlmans van Emmichoven. Strongly reduced penetration of atomic deuterium in radiation-damaged tungsten. Phys. Rev. Lett., 111:225001, Nov 2013.

[8] E.A. Hodille, A. Založnik, S. Markelj, T. Schwarz-Selinger, C.S. Becquart, R. Bisson, and C. Grisolia. Simulations of atomic deuterium exposure in self-damaged tungsten. Nuclear Fusion, 57(5):056002, 2017.

[9] Anže Založnik, Sabina Markelj, Thomas Schwarz-Selinger, and Klaus Schmid. Deuterium atom loading of self- damaged tungsten at different sample temperatures. Journal of Nuclear Materials, 496:1 - 8, 2017.

[10] Matic Pečovnik, Sabina Markelj, Anže Založnik, and Thomas Schwarz-Selinger. Influence of grain size on deuterium transport and retention in self-damaged tungsten. Journal of Nuclear Materials, 513:198 - 208, 2019.

[11] Jerome Guterl, R.D. Smirnov, and P. Snyder. Effects of surface processes on hydrogen outgassing from metal in desorption experiments. Nuclear Fusion, 59(9):096042, aug 2019.

[12] M.A. Pick and K. Sonnenberg. A model for atomic hydrogen-metal interactions application to recycling, recombination and permeation. Journal of Nuclear Materials, 131(2):208 - 220, 1985.

[13] P. W. Tamm and L. D. Schmidt. Binding states of hydrogen on tungsten. The Journal of Chemical Physics, 54(11):4775-4787, 1971.

[14] P. Alnot, A. Cassuto, and D.A. King. Adsorption and desorption kinetics with no precursor trapping: Hydrogen and deuterium on w 100. Surface Science, 215(1):29 - 46, 1989.

[15] T.-U. Nahm and R. Gomer. The adsorption of hydrogen on $\mathrm{w}(110)$ and fe covered w(110) surfaces. Surface Science, $375(2): 281-292,1997$.

[16] Sabina Markelj, Olga V. Ogorodnikova, Primož Pelicon, Thomas Schwarz-Selinger, and Iztok Čadež. Temperature dependence of $\mathrm{d}$ atom adsorption on polycrystalline tungsten. Applied Surface Science, 282:478 - 486, 2013.

[17] Z.A. Piazza, M. Ajmalghan, Y. Ferro, and R.D. Kolasinski. Saturation of tungsten surfaces with hydrogen: A density functional theory study complemented by low energy ion scattering and direct recoil spectroscopy data. Acta Materialia, 145:388-398, 2018. cited By 2.

[18] M. Ajmalghan, Z.A. Piazza, E.A. Hodille, and Y. Ferro. Surface coverage dependent mechanisms for the absorption and desorption of hydrogen from the w(110) and $\mathrm{w}(100)$ surfaces: a density functional theory investigation. Nuclear Fusion, 59(10):106022, aug 2019.

[19] Z J Bergstrom, C Li, G D Samolyuk, B P Uberuaga, and B D Wirth. Hydrogen interactions with low-index surface orientations of tungsten. Journal of Physics: Condensed Matter, 31(25):255002, apr 2019.

[20] S. Markelj, T. Schwarz-Selinger, A. Založnik, M. Kelemen, P. Vavpetič, P. Pelicon, E. Hodille, and C. Grisolia. Deuterium retention in tungsten simultaneously damaged by high energy $\mathrm{w}$ ions and loaded by d atoms. Nuclear $\mathrm{Ma-}$ terials and Energy, 12:169 - 174, 2017. Proceedings of the 22nd International Conference on Plasma Surface Interactions 2016, 22nd PSI.

[21] S. Markelj, A. Zaloznik, M. Kelemen, P. Vavpetic, P. Pelicon, T. Schwarz-Selinger, O. V. Ogordnikova, L. Ciupinski, and J. Grzonka. Deuterium retention studies in self-ion damaged tungsten exposed to neutral atoms. Proceedings of 24th Internation Conference Nuclear Energy for New Europe, 2015 Portoroz, Slovenija, 2015.

[22] N. Fernandez, Y. Ferro, and D. Kato. Hydrogen diffusion and vacancies formation in tungsten: Density functional theory calculations and statistical models. Acta Materialia, 94:307 - 318, 2015.

[23] K. Heinola, T. Ahlgren, K. Nordlund, and J. Keinonen. Hydrogen interaction with point defects in tungsten. Phys. Rev. B, 82:094102, Sep 2010.

[24] Donald F. Johnson and Emily A. Carter. Hydrogen in tungsten: Absorption, diffusion, vacancy trapping, and decohesion. Journal of Materials Research, 25(2):315327, 2010.

[25] Yue-Lin Liu, Hong-Bo Zhou, and Ying Zhang. Investigating behaviors of $\mathrm{h}$ in a $\mathrm{w}$ single crystal by first-principles: 
From solubility to interaction with vacancy. Journal of Alloys and Compounds, 509(33):8277 - 8282, 2011.

[26] J. Hou, X. Kong, and X. Wu. nature materials, 18:833-839, 2019.

[27] K. Schmid, U. von Toussaint, and T. Schwarz-Selinger. Transport of hydrogen in metals with occupancy dependent trap energies. Journal of Applied Physics, 116(13):134901, 2014.

[28] E A Hodille, Y Ferro, N Fernandez, C S Becquart, T Angot, J M Layet, R Bisson, and C Grisolia. Study of hydrogen isotopes behavior in tungsten by a multi trapping macroscopic rate equation model. Physica Scripta, 2016(T167):014011, 2016.

[29] D. Matveev, M. Wensing, L. Ferry, F. Virot, M. Barrachin, Y. Ferro, and Ch. Linsmeier. Reaction-diffusion modeling of hydrogen transport and surface effects in application to single-crystalline be. Nuclear Instruments and Methods in Physics Research Section B: Beam Interactions with Materials and Atoms, 430:23 - 30, 2018.

[30] E.A. Hodille, F. Ghiorghiu, Y. Addab, A. Založnik, M. Minissale, Z. Piazza, C. Martin, T. Angot, L. Gallais, M.-F. Barthe, C.S. Becquart, S. Markelj, J. Mougenot, C. Grisolia, and R. Bisson. Retention and release of hydrogen isotopes in tungsten plasma-facing components: the role of grain boundaries and the native oxide layer from a joint experiment-simulation integrated approach. Nuclear Fusion, 57(7):076019, 2017.

[31] Matic Peovnik, Etienne A Hodille, Thomas SchwarzSelinger, Christian Grisolia, and Sabina Markelj. New rate equation model to describe the stabilization of displacement damage by hydrogen atoms during ion irradiation in tungsten. Nuclear Fusion, 2020.

[32] L. Yang and B. D. Wirth. Energetics of hydrogen and helium-vacancy complexes in bulk and near surfaces of tungsten: First-principles study. Journal of Applied Physics, 123(21):215104, 2018.

[33] Yoshiki Hamamoto, Takeru Uchikoshi, and Katsuaki Tanabe. Comprehensive modeling of hydrogen transport and accumulation in titanium and zirconium. Nuclear Materials and Energy, 23:100751, 2020.

[34] A. C. Hindmarsh. Odepack, a systemaized collection of ode solvers. Scientific Computing, R. S. Stepleman et al. (eds.), North Holland, Amsterdam, (vol. 1 of IMACS Transactions on Scientific Computation), pages 55-64, 1983.

[35] K Radhakrishnan and A C Hindmarsh. Description and use of lsode, the livemore solver for ordinary differential equations. 121993.

[36] E.A. Hodille, S. Markelj, T. Schwarz-Selinger, A. Založnik, M. Pečovnik, M. Kelemen, and C. Grisolia. Stabilization of defects by the presence of hydrogen in tungsten: simultaneous w-ion damaging and d-atom exposure. Nuclear Fusion, 59(1):016011, nov 2018.

[37] O. V. Ogorodnikova, S. Markelj, and U. von Toussaint. Interaction of atomic and low-energy deuterium with tungsten pre-irradiated with self-ions. Journal of Applied Physics, 119(5):054901, 2016.

[38] S. Markelj, A. Založnik, T. Schwarz-Selinger, O.V. Ogorodnikova, P. Vavpetič, P. Pelicon, and I. Čadež. In situ nra study of hydrogen isotope exchange in self-ion damaged tungsten exposed to neutral atoms. Journal of Nuclear Materials, 469:133 - 144, 2016.

[39] Eric Jones, Travis Oliphant, Pearu Peterson, et al. SciPy: Open source scientific tools for Python, 2001-.

[40] Pauli Virtanen, Ralf Gommers, Travis E. Oliphant, Matt Haberland, Tyler Reddy, David Cournapeau, Evgeni Burovski, Pearu Peterson, Warren Weckesser, Jonathan Bright, Stéfan J. van der Walt, Matthew Brett, Joshua Wilson, K. Jarrod Millman, Nikolay Mayorov, Andrew
R. J. Nelson, Eric Jones, Robert Kern, Eric Larson, C. J. Carey, Illhan Polat, Yu Feng, Eric W. Moore, Jake VanderPlas, Denis Laxalde, Josef Perktold, Robert Cimrman, Ian Henriksen, E. A. Quintero, Charles R. Harris, Anne M. Archibald, Antônio H. Ribeiro, Fabian Pedregosa, and Paul van Mulbregt. SciPy 1.0: fundamental algorithms for scientific computing in Python. Nature Methods, 17(3), March 2020.

[41] Y. Yamada, K.-H. Rieder, and W. Theis. Surface phase transition in $\mathrm{H} / \mathrm{W}(110)$ induced by tuning the fermi surface nesting vector by hydrogen loading. Phys. Rev. Lett., 99:196105, Nov 2007.

[42] K. Heinola and T. Ahlgren. First-principles study of h on the reconstructed $\mathrm{w}(100)$ surface. Phys. Rev. B, 81:073409, Feb 2010

[43] J. W. Davenport, G. J. Dienes, and R. A. Johnson. Surface effects on the kinetics of hydrogen absorption by metals. Phys. Rev. B, 25:2165-2174, Feb 1982.

[44] R. Frauenfelder. Solution and diffusion of hydrogen in tungsten. Journal of Vacuum Science and Technology, 6(3):388-397, 1969.

[45] J. Denis, J. Bucalossi, G. Ciraolo, E.A. Hodille, B. Pégourié, H. Bufferand, C. Grisolia, T. Loarer, Y. Marandet, and E. Serre. Dynamic modelling of local fuel inventory and desorption in the whole tokamak vacuum vessel for autoconsistent plasma-wall interaction simulations. Nuclear Materials and Energy, 19:550 - 557, 2019.

[46] Oihana Galparsoro, Rémi Pétuya, Fabio Busnengo, Joseba Iaki Juaristi, Cédric Crespos, Maite Alducin, and Pascal Larregaray. Hydrogen abstraction from metal surfaces: when electronhole pair excitations strongly affect hot-atom recombination. Phys. Chem. Chem. Phys., 18:31378-31383, 2016.

[47] Galparsoro O., Pétuya R., Juaristi J. I., Crespos C., Alducin M., and Larrégaray P. Energy Dissipation to Tungsten Surfaces upon EleyRideal Recombination of $\mathrm{N} 2$ and H2. The Journal of Physical Chemistry C, 119(27):1543415442, 2015. doi: 10.1021/acs.jpcc.5b04286.

[48] R. Pétuya, P. Larrégaray, C. Crespos, P. Aurel, H. F. Busnengo, and A. E. Martnez. Scattering of atomic hydrogen off a h-covered $\mathrm{w}(110)$ surface: Hot-atom versus eleyrideal abstraction dynamics. The Journal of Physical Chemistry C, 119(6):3171-3179, 2015.

[49] P.N. Maya. Molecular dynamics studies of sticking and reflection of low-energy deuterium on single crystal tungsten. Journal of Nuclear Materials, 480:411 - 419, 2016.

[50] R. Bisson, S. Markelj, O. Mourey, F. Ghiorghiu, K. Achkasov, J.-M. Layet, P. Roubin, G. Cartry, C. Grisolia, and T. Angot. Dynamic fuel retention in tokamak wall materials: An in situ laboratory study of deuterium release from polycrystalline tungsten at room temperature. Journal of Nuclear Materials, 467:432438, 2015.

[51] L. Gao, W. Jacob, U. von Toussaint, A. Manhard, M. Balden, K. Schmid, and T. Schwarz-Selinger. Deuterium supersaturation in low-energy plasma-loaded tungsten surfaces. Nuclear Fusion, 57(1):016026, 2017.

[52] E. A. Hodille, N. Fernandez, Z. A. Piazza, M. Ajmalghan, and Y. Ferro. Hydrogen supersaturated layers in h/d plasma-loaded tungsten: A global model based on thermodynamics, kinetics and density functional theory data. Phys. Rev. Materials, 2:093802, Sep 2018.

[53] Z. A. Piazza, M. Ajmalghan, R. Kolasinski, and Y. Ferro. A density functional theory based thermodynamic model of hydrogen coverage on the w(110) surface. Accpeted in Physica Scripta, 2019.

[54] Muthali Ajmalghan. Electronic Structure Calculations and Thermodynamic Models for Energy-producing Systems. 
Theses, UNIVERSITE D'AIX-MARSEILLE, September 2019.

[55] M.R. Gilbert, S.L. Dudarev, S. Zheng, L.W. Packer, and J.-Ch. Sublet. An integrated model for materials in a fusion power plant: transmutation, gas production, and helium embrittlement under neutron irradiation. Nuclear Fusion, 52(8):083019, aug 2012.

[56] K Schmid. Diffusion-trapping modelling of hydrogen recycling in tungsten under elm-like heat loads. Physica Scripta, 2016(T167):014025, 2016

[57] J. D. Hunter. Matplotlib: A 2d graphics environment. Computing in Science \& Engineering, 9(3):90-95, 2007.

[58] Anže Založnik, Sabina Markelj, Thomas Schwarz-Selinger, ukasz Ciupiski, Justyna Grzonka, Primož Vavpetič, and Primož Pelicon. The influence of the annealing temperature on deuterium retention in self-damaged tungsten. Physica Scripta, 2016(T167):014031, 2016.

[59] O.V. Ogorodnikova and V. Gann. Simulation of neutroninduced damage in tungsten by irradiation with energetic self-ions. Journal of Nuclear Materials, 460:60 - 71, 2015. 